\title{
Syntheses and Electronic Applications of Helical Carbon Nanofibres
}

\author{
Yoshiyuki Suda, Hirofumi Takikawa and Hideto Tanoue \\ Toyohashi University of Technology \\ Japan
}

\section{Introduction}

Helical carbon nanofibre (HCNF) is spiral-shaped carbon nanofibre (CNF) with coil and fibre diameters in the range of $20-1000 \mathrm{~nm}$ and 5-400 $\mathrm{nm}$, respectively. The unique three-dimensional structure of HCNFs induces a lot of researches to apply HNCFs to electrical and electronic engineering as well as mechanical engineering. Carbon nanotubes (CNTs) were first discovered in the soot produced by an arc discharge and laser ablation has been one of the most reliable methods to prepare high-quality CNTs. On the other hand, HCNFs has been almost entirely grown by chemical vapour deposition (CVD) using hydrocarbon feedstock gases. In this chapter, we describe the history, classification, synthesis, and application of HCNFs. We mainly introduce our research results including the latest topics, comparing with the other group's work. The problems that still remain in the CVD growth and the future researches of HCNFs we intend are also discussed.

\section{History of HCNFs}

In 1953, Davis et al. have found minute vermicular growths of carbon through the experimental work on the deposition of carbon in the brickwork of blast furnaces (Davis et al., 1953). In 1955, Hofer et al. reported the growth of carbon filaments with fibre diameters of 10 to $200 \mathrm{~nm}$. They used the catalytic deposition technique of carbon from carbon monoxide by the following disproportionation reaction.

$$
2 \mathrm{CO} \rightarrow \mathrm{C}+\mathrm{CO}_{2}
$$

At atmosphere pressure, the reaction takes place between 300 and $800^{\circ} \mathrm{C}$. They used Ni, Co, and $\mathrm{Fe}$ as a catalyst and a combustion tube with an electric furnace for the carbon growth. Carbon filaments grew on all of the catalysts at $390^{\circ} \mathrm{C}$, and the deposits on Fe were single solid strands. They also found that the filaments were extended in two directions from central catalyst particles (Hofer et al., 1955).

Boehm intended to find a continuous process of carbon filaments by feeding metal carbonyl into a $\mathrm{CO}$ stream before it passed a heated tube. He introduced $\mathrm{Ni}(\mathrm{CO})_{4^{-}}$or $\mathrm{Fe}(\mathrm{CO})_{5^{-}}$ containing $\mathrm{CO}(80 \%) / \mathrm{H}_{2}(20 \%)$ gas mixture into the heated zone of a heat-resistant glass tube with an electric furnace at temperatures of $550-770^{\circ} \mathrm{C}$. When $\mathrm{Fe}(\mathrm{CO})_{5}$ was used, the 
usual fibril with twisted strands was grown at $600-650^{\circ} \mathrm{C}$. In an electron microscopy observation, he found that twisted filaments very often form double or even triple helices (Boehm, 1973).

Though the $\mathrm{CO}$ disproportionation reaction is a reliable method to synthesize carbon filaments including commercially-available CNTs (http://www.unidym.com/), it is highly deleterious in several industrial processes (Hofer et al., 1955). Baker et al. developed the catalytic decomposition of $\mathrm{C}_{2} \mathrm{H}_{2}$ gas over catalyst surfaces and studied the effect of $\mathrm{Sn}$ on the growth of filaments from the $\mathrm{Fe} / \mathrm{C}_{2} \mathrm{H}_{2}$ system. In this system, significant deposit growth of carbon filaments was only observed at temperatures above $800^{\circ} \mathrm{C}$ with $\mathrm{Sn}$-coated Fe foils in a 665-Pa $\mathrm{C}_{2} \mathrm{H}_{2}$. They found that the filaments were nearly all spirals with a constant pitch and the Fe/Sn alloy worked to form spiral filaments. On pure iron, deposits grew at temperatures as low as $650^{\circ} \mathrm{C}$; however, it became autolytically poisoned after a few minutes. The growth still continued on $\mathrm{Fe} / \mathrm{Sn}$ after more than $2 \mathrm{~h}$, and poisoning was never observed (Baker et al., 1975).

Motojima et al. have grown regularly coiled carbon filaments by the catalytic pyrolysis of $\mathrm{C}_{2} \mathrm{H}_{2}$ at $350-750^{\circ} \mathrm{C}$ using Ni plate and powder as a catalyst (Motojima et al., 1990). His group also succeeded to grow very regularly coiled spring-like fibres of $\mathrm{Si}_{3} \mathrm{~N}_{4}$ from a gas mixture of $\mathrm{Si}_{2} \mathrm{Cl}_{6}, \mathrm{NH}_{3}$, and $\mathrm{H}_{2}$ at $1200^{\circ} \mathrm{C}$ on a graphite substrate on which an iron impurity was painted (Motojima et al., 1989). These results show that various types of helical nanofibres including HCNFs can be grown if the suitable combination of catalyst and source gas is found.

These findings were published prior to the discovery of multi-walled CNTs (MWCNTs) (Iijima, 1991) and single-walled CNTs (SWCNTs), (Iijima \& Ichihashi, 1993). CNTs consist of concentrically rolled-up graphitic layers and have relatively smaller dimensions than CNFs (Saito et al., 1998). CNTs were discovered in the soot produced by an arc discharge, and arc discharge and laser ablation of catalyst metals-containing graphite rod have been excellent methods to synthesize high-quality SWCNTs (Journet et al., 1997), (Thess et al., 1996). In 1998, growth of SWCNTs by CVD was successfully realized by Kong et al. (Kong et al., 1998) and subsequently CVD has become a dominant technique in the CNT research and development. Concurrently with the development of SWCNT synthesis by CVD, very thin HCNF which has a hollow structure with several concentric graphitic layers were formed by Ivanov et al. (Ivanov et al., 1994). This structure is called multi-walled carbon nanocoil (MWCNC) and described in Section 7.

Zhang of the Prof. Nakayama's group intended to fabricate HCNFs in high yield and tried to deposit $\mathrm{Fe}$ on indium-tin-oxide (ITO) substrate instead of $\mathrm{Fe} / \mathrm{Sn}$ system. They successfully grew $\mathrm{HCNFs}$ using $\mathrm{C}_{2} \mathrm{H}_{2} / \mathrm{He}$ gas mixture at $700^{\circ} \mathrm{C}$. It is noted that more than $95 \%$ of carbon deposits grew helically on the ITO substrate (Zhang et al., 2000).

Takikawa et al. used a hot-filament CVD apparatus to enhance the carbon deposition efficiency and to lower growth temperature $\left(550-600^{\circ} \mathrm{C}\right), \mathrm{Cu}$ as a substrate, and $\mathrm{C}_{2} \mathrm{H}_{4}$ as a carbon feedstock gas. HCNF with an inner diameter (called carbon nanocoil, $\mathrm{CNC}$ ) grew on Ni-coated $\mathrm{Cu}$ substrate at $550^{\circ} \mathrm{C}$, and $\mathrm{HCNF}$ without an inner diameter (called carbon nanotwist, $\mathrm{CNTw}$ ) grew on $\mathrm{Zn}$-coated $\mathrm{Cu}$ substrate at $600^{\circ} \mathrm{C}$. It was the first time that $\mathrm{Zn}$ (or $\mathrm{ZnO}_{\mathrm{x}}$ ) was found to be a possible catalyst for HCNFs growth (Takikawa et al., 2000). Hereafter, a lot of catalyst combinations for the growth of HCNFs have been reported, as explained in Section 4.3. 


\section{Classification}

Figure 1 shows scanning electron microscopy (SEM) micrographs of HCNFs. HCNFs can be categorized into three types by the inner diameter and fibre cross section: (1) carbon nanocoil (CNC) which has a spiral spring shape with an inner diameter; (2) carbon nanotwist $(\mathrm{CNTw})$ which has a twisted shape without an inner diameter; and (3) multiwalled carbon nanocoil (MWCNC) whose diameter is typically smaller than $50 \mathrm{~nm}$ with a hollow structure of concentric graphitic layers. Both $\mathrm{CNTw}$ and $\mathrm{CNC}$ have angular and round types. MWCNC is typically the round type.

See more information about the classifications of HCNFs, carbon microcoil (CMC) which has a coil diameter $\geq 1 \mu \mathrm{m}$, and coiled CNT in the following review papers (Motojima \& Chen 2004), (Hanus \& Harris 2010).

\section{Experimental}

\subsection{CVD apparatus for HCNF growth}

Here we introduce a CVD apparatus for HCNF growth in our laboratory. The apparatus consist of a quartz tube (45 mm inner diameter and $500 \mathrm{~mm}$ long), an electric furnace, and gas supply system. The quartz tube and electric furnace are horizontally arranged. Catalyst for HCNF growth, which is deposited on substrate or supported on mesoporous materials is placed in the centre of the quartz tube and heated up to a desired temperature (typically $\leq$ $800^{\circ} \mathrm{C}$ ) under the flow of dilute gas $\left(\mathrm{He}\right.$ or $\left.\mathrm{N}_{2}\right)$. Hydrocarbon feedstock gas $\left(\mathrm{C}_{2} \mathrm{H}_{2}\right.$ or $\left.\mathrm{C}_{2} \mathrm{H}_{4}\right)$ is added to the dilute gas when HCNF is grown. Flow rates of the gases are controlled with a mass flow controller. The exhaust gas through the quartz tube is firstly collected into the bubbler tube and then evacuated.

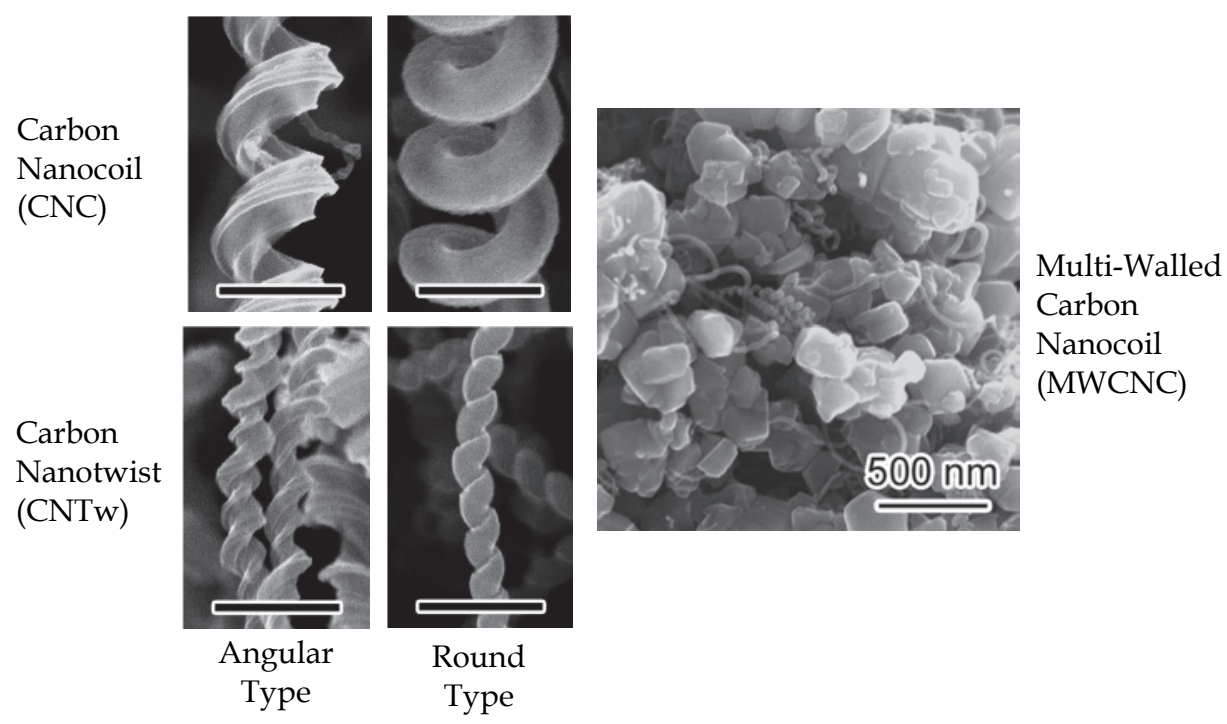

Fig. 1. SEM micrographs of HCNFs. Scale bar: $500 \mathrm{~nm}$. 


\title{
4.2 Development of automatic CVD system for mass production
}

Based on the experimental results of HCNF growth using the CVD apparatus, Prof. Takikawa developed an automatic CVD system with a consecutive substrate transfer mechanism for mass production of HCNFs (Hosokawa et al., 2007). Schematic of the CVD system is shown in Figure 2. The system is composed of substrate loading chamber, transfer chamber, process reactor with electric furnace, and cooling chamber. Two gate valves separate the loading, transfer, and cooling chambers. No separation exists between the transfer chamber and the process reactor. All chambers are made of stainless steel, except a perpendicularly placed process reactor (quartz tube, $94 \mathrm{~mm}$ inner diameter). A substrate cassette containing up to 8 substrates of $70 \mathrm{~mm}$ in diameter is placed in the loading chamber. Each substrate is then transferred from the cassette to the process reactor by the cassette-elevator robot-arm, horizontal robot-arm, and vertical robot-arm. After the reaction, the substrate is transferred to the cooling stage in the cooling chamber. The cooling stage has a rotary actuator, and the substrate is dropped to the bottom of the collection pot after sufficient cooling. This procedure is controlled by a sequencer, and the substrates are one by one transferred and treated while keeping the furnace temperature in the process condition.

\subsection{Catalyst preparation}

In CVD process, catalyst is needed to synthesis carbon nanomaterials including CNFs, HCNFs, CNTs, and graphene. (Jong \& Geus 2000), (Motojima \& Chen 2004), (Hanus \& Harris 2010), (Kumar \& Ando 2010), (Yu et al., 2008) Multi-walled CNTs and carbon nanoparticles can be formed from vaporised carbon in arc discharge or laser ablation. Metals that dissolve carbon are usually used as a catalyst of carbon nanomaterials. As stated in Section 2, Baker found the effect of binary-catalyst on HCNF growth, and then various combinations of binary-catalysts for HCNF growth have been found, e.g. Fe/ITO (Zhang et al., 2000), Fe/ $\mathrm{SnO}_{2}$ (Chen et al., 2004), (Xu et al., 2005), Fe/Sn (Hokshin et al., 2007), Fe-based

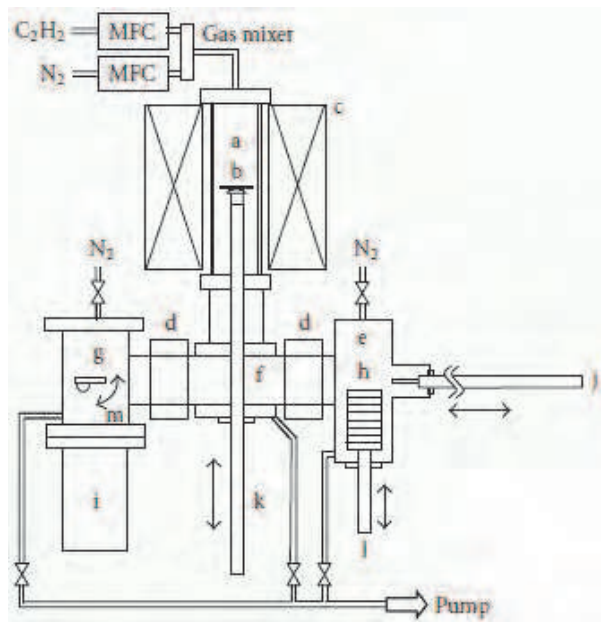

\author{
(a) Reactor quartz tube (94 i.d) \\ (b) Substrate (70 o.d.) \\ (c) Electric furnace \\ (d) Gate valve \\ (e) Loading chamber \\ (f) Transfer chamber \\ (g) Cooling chamber \\ (h) Substrate cassette \\ (i) Collection pot \\ (i) Horizontal robot-arm \\ (k) Vertical robot-arm \\ (1) Cassette elevator robot-arm \\ (m) Rotary actuatot
}

Fig. 2. Schematic diagram of automatic CVD system with a consecutive substrate transfer mechanism. (Hosokawa et al., 2007) 
alloys (Fe-Cr-Mn-Mo, Fe-Cr-Ni-Mo (SUS513), Fe-Ni-Cr-Mo-Mn-Sn) (Yang et al., 2004), (Yang et al., 2005), $\mathrm{Ni} / \mathrm{SnO}_{2}$ (Hosokawa et al., 2007), Ni/Sn (Yokota et al., 2010), $\mathrm{Cu}-(\mathrm{Ni}, \mathrm{Cr}$, Ti or Zn) (Takikawa et al., 2000), and Ni/Cu (Katsumata et al., 2004).

According to our experimental results, it is possible to grow $\mathrm{CNC}$ and $\mathrm{CNTw}$ selectively by the combination of binary catalyst; CNC is synthesized by Fe-based catalyst, and CNTw synthesized by Ni-based catalyst. In this chapter, the results of HCNF growths by Fe/Sn and $\mathrm{Ni} / \mathrm{Sn}$ catalysts are mainly introduced. Fe and Ni are well-known to dissolve carbon, whereas Sn cannot dissolve carbon.

\subsection{HCNF growth conditions}

The CVD conditions used in our study are listed in Table 1. It does not make much sense to determine "the best" condition because CVD condition strongly depends on CVD apparatus, dimension of the chamber and type and amount of the catalysts. Here we introduce commonly-used CVD conditions. The feedstock gas mainly used was $\mathrm{C}_{2} \mathrm{H}_{2}$ and diluted with $\mathrm{He}$ or $\mathrm{N}_{2}$ gas. The temperature range was broad, $400-800^{\circ} \mathrm{C}$ because catalytic decomposition of $\mathrm{C}_{2} \mathrm{H}_{2}$ takes place even below $400^{\circ} \mathrm{C}$. Optimum temperatures for the growth of $\mathrm{CNC}$ and $\mathrm{CNTw}$ were determined through the number of growth experiments using our apparatus. The reaction time was set to mostly $10 \mathrm{~min}$. During this time period, growth of CNF is constant. Various types of catalysts were tried and their results were described in each section.

\begin{tabular}{cccc}
\hline $\begin{array}{c}\text { Feedstock gas } \\
\text { (flow rate) }\end{array}$ & $\begin{array}{c}\text { Dilute gas } \\
\text { (flow rate })\end{array}$ & Temp. & Reaction time \\
$\mathrm{C}_{2} \mathrm{H}_{2}(50-350 \mathrm{ml} / \mathrm{min})$ & $\begin{array}{c}\mathrm{He}(400-1000 \mathrm{ml} / \mathrm{min}) \\
\mathrm{N}_{2}(1000-1400 \mathrm{ml} / \mathrm{min})\end{array}$ & $400-800^{\circ} \mathrm{C}$ & $10-30 \mathrm{~min}$ \\
\hline $\mathrm{Catalyst}$ & Substrate & Reference \\
$\mathrm{Ni}, \mathrm{Zn}$ & $\mathrm{Cu}$ & Takikawa et al., 2000 \\
$\mathrm{Ni} / \mathrm{Cu}, \mathrm{NiO} / \mathrm{CuO}$ & Quartz & Katsumata et al., 2004 \\
$\mathrm{Fe} / \mathrm{SnO}_{2}$ & Quartz & Xu et al., 2005 \\
$\mathrm{Ni} / \mathrm{SnO}{ }_{2}$ & Graphite & Hosokawa et al., 2007 \\
$\mathrm{Fe} / \mathrm{Sn}, \mathrm{Ni} / \mathrm{Sn}$ & Graphite & Hosokawa et al., 2008 \\
$\mathrm{Fe} / \mathrm{Sn}$ & Zeolite & Yokota et al., 2010 \\
\hline
\end{tabular}

Table 1. CVD conditions for HCNF growth.

\subsection{Characterisation}

After the reaction, the carbon deposit was weighed using an analytical balance. For the asgrown carbon deposit mixed with the catalyst, the carbon deposition rate was calculated as follows:

$$
\text { Deposition rate of carbon }=\left\{\left(W_{\text {tot }}-W_{\text {cat }}\right) / W_{\text {cat }}\right\} / \text { time }
$$

where $W_{\text {tot }}$ is the total weight of the catalyst and the carbon deposit, $W_{\text {cat }}$ is the weight of the catalyst, and time is the duration of $\mathrm{C}_{2} \mathrm{H}_{2}$ introduction. Therefore, the deposition rate reveals the carbon yield per unit weight of the catalyst per unit time. 
The carbon deposit was observed using a field emission scanning electron microscope (FESEM) (S-4500II, Hitachi), an energy dispersive X-ray analyser (EDX) (DX-4, Phillips) and transmission electron microscopes (TEM) (JEM-2010 and JEM-2100F, JEOL). The deposit was then evaluated based on its HCNF purity estimated from several visual fields in the SEM micrographs. The fibre diameters, the coil diameters and the coil pitches of HCNFs were also measured on the SEM micrographs.

The field emission properties of HCNFs were measured in a vacuum chamber and the apparatus used is described in Section 8.

\section{Quantity synthesis of HCNFs}

\subsection{Parametric study on growth of carbon nanocoil}

\subsubsection{Effects of catalyst composition}

In order to determine the optimum composition of the Fe/Sn catalyst, the Fe percentage over the total weight of $\mathrm{Fe}$ and $\mathrm{SnO}_{2}$ was adjusted from 0 to $100 \%$ at steps of $10 \%$. The catalytic performance of every combination was evaluated based on the deposition rate and the SEM micrograph of carbon deposits under identical conditions. The reaction was carried out at $700^{\circ} \mathrm{C}$ for $10 \mathrm{~min}$ with flow rates of $\mathrm{C}_{2} \mathrm{H}_{2}$ and $\mathrm{He}$ at 180 and $420 \mathrm{ml} / \mathrm{min}$, respectively. Figure 3 shows that the carbon deposition rate increases with the Fe percentage. There are no significant depositions on pure $\mathrm{Fe}$ and pure $\mathrm{SnO}_{2}$. With the catalysts having Fe percentages between 60 and $90 \%$, carbon deposition rates saturate to approximately 4 min $^{-1}$. This means that 40 times of carbon materials were deposited on one portion of catalyst in 10 min under the given process conditions.

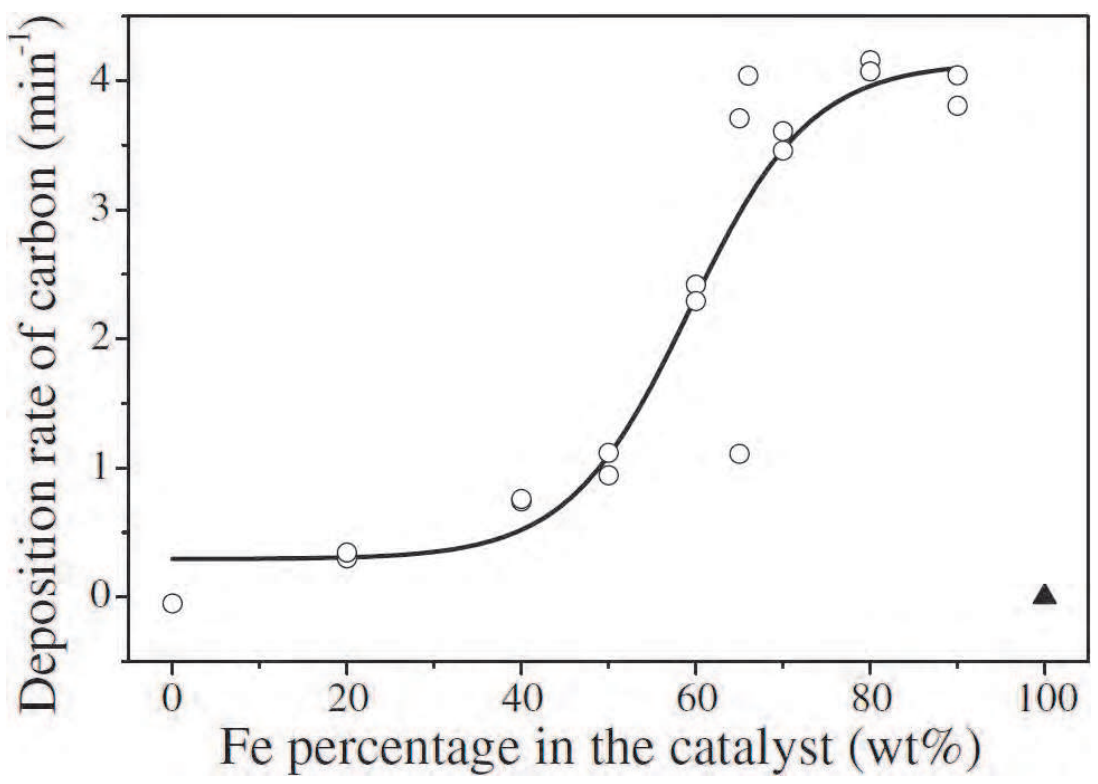

Fig. 3. Deposition rates of carbon materials on the composition of the catalyst. Pyrolysis of $\mathrm{C}_{2} \mathrm{H}_{2}$ was carried out on $10 \mathrm{mg}$ mixture of $\mathrm{Fe}$ and $\mathrm{SnO}_{2}$ at $700^{\circ} \mathrm{C}$ for $10 \mathrm{~min}$ with the flow rates of $\mathrm{C}_{2} \mathrm{H}_{2}$ and $\mathrm{He}$ gases of 180 and $420 \mathrm{ml} / \mathrm{min}$, respectively. (Xu et al., 2005) 
Figure 4 shows SEM micrographs of carbon materials deposited on catalysts of various compositions. On the catalyst with $20 \% \mathrm{Fe}$, as shown in (a), no significant carbon deposition can be observed. On the catalysts with $40 \%, 50 \%$, and $60 \% \mathrm{Fe}$ in (b), (c), and (d), respectively, twisted fibres dominate the visual fields of the micrographs. On the catalysts of $67 \%$ (e), $70 \%$ (f), and $80 \%$ (g) Fe, CNCs are found to be the main components of the deposits, the fibre diameters of the CNCs grown from the catalyst with $67 \%$ Fe are distributed from $50 \mathrm{~nm}$ to $300 \mathrm{~nm}$. CNC percentages lessen with further increase of the Fe ratio, and CNCs can rarely be found among the short fibres grown from the catalyst with $90 \%$ Fe. From the micrographs, we also notice that fibre diameters tend to become smaller with increasing $\mathrm{SnO}_{2}$ ratio. These results reveal that $\mathrm{CNC}$ selectivity is solely dependent on catalyst composition and that the optimum combination of the catalyst with high CNC selectivity as well as carbon deposition activity lies within a rather narrow range.

\subsubsection{Influences of reaction temperature}

Because the catalyst with $67 \mathrm{wt} \% \mathrm{Fe}$ in a mixture with $\mathrm{SnO}_{2}$ gave the highest selectivity for $\mathrm{CNC}$ formation as well as the highest deposition yield under the given experimental conditions, it was chosen for the optimisation of reaction temperature from 400 to $800^{\circ} \mathrm{C}$. Carbon yield and $\mathrm{CNC}$ selectivity at different temperatures were evaluated after a reaction of $30 \% \mathrm{C}_{2} \mathrm{H}_{2}$ in a mixture with He for $10 \mathrm{~min}$.

Figure 5 presents carbon deposition rates at different reaction temperatures. At temperatures below $675^{\circ} \mathrm{C}$, the carbon deposition rate increases with temperature. On the contrary, carbon deposition rate decreases with rising temperature $>725^{\circ} \mathrm{C}$. The optimum temperatures for obtaining high carbon yields lie in the range between 625 and $725^{\circ} \mathrm{C}$.

Similar optimum temperatures were also reported for other catalyst systems such as iron carbide doped with tin monoxide (Hernadi et al., 2002), Fe-coated ITO (Zhang et al., 2000), and Sn-coated Fe foil. (Baker et al., 1975)

Figure 6 shows SEM micrographs of carbon deposits formed on the catalyst at different reaction temperatures. At $500^{\circ} \mathrm{C}$, as shown in (a), small amounts of amorphous carbon are observed on the catalyst particles. At $600^{\circ} \mathrm{C}$ in (b), carbon nanofibres (CNFs) and CNCs are found to be mixed with the amorphous carbon. With increasing reaction temperature, the amount of amorphous carbon decreases and CNC selectivity increases steadily until $700^{\circ} \mathrm{C}$. Further elevation of the temperature results in the decrease of CNC selectivity and the increase of $\mathrm{CNF}$ yield. At $700^{\circ} \mathrm{C}(\mathrm{e}), \mathrm{CNCs}$ with a broad coil diameter distributions ranging from as thin as $10 \mathrm{~nm}$ to as thick as $600 \mathrm{~nm}$ are formed at high selectivity.

These results reveal that $\mathrm{CNC}$ selectivity is very sensitive to reaction temperature, and that $700^{\circ} \mathrm{C}$ is the optimum temperature for both CNC selectivity and carbon deposition rate under the given experimental conditions.

\subsubsection{Effects of helium gas addition}

To optimise gas composition for CNC formation, the flow rates of $\mathrm{He}$ and $\mathrm{C}_{2} \mathrm{H}_{2}$ were regulated at 400-1000 and 50-300 ml/min, respectively. The catalyst with an Fe percentage of $67 \%$ and the reaction temperature of $700^{\circ} \mathrm{C}$ were fixed for each batch. Carbon yield and CNC selectivity at different gas compositions were evaluated after the reaction for $10 \mathrm{~min}$.

Figure 7 shows the plot of the carbon deposition rate versus the partial pressure of $\mathrm{C}_{2} \mathrm{H}_{2}$ gas in a mixture with He gas. When the partial pressure of the $\mathrm{C}_{2} \mathrm{H}_{2}$ gas rises from 0.1 to 0.2 , carbon deposition rate attains to a maximum, and decreases with further increase of the partial pressure of the $\mathrm{C}_{2} \mathrm{H}_{2}$ gas beyond 0.3. The carbon deposition rate maximizes when the partial pressure of the $\mathrm{C}_{2} \mathrm{H}_{2}$ gas is between 0.2 and 0.3 . 

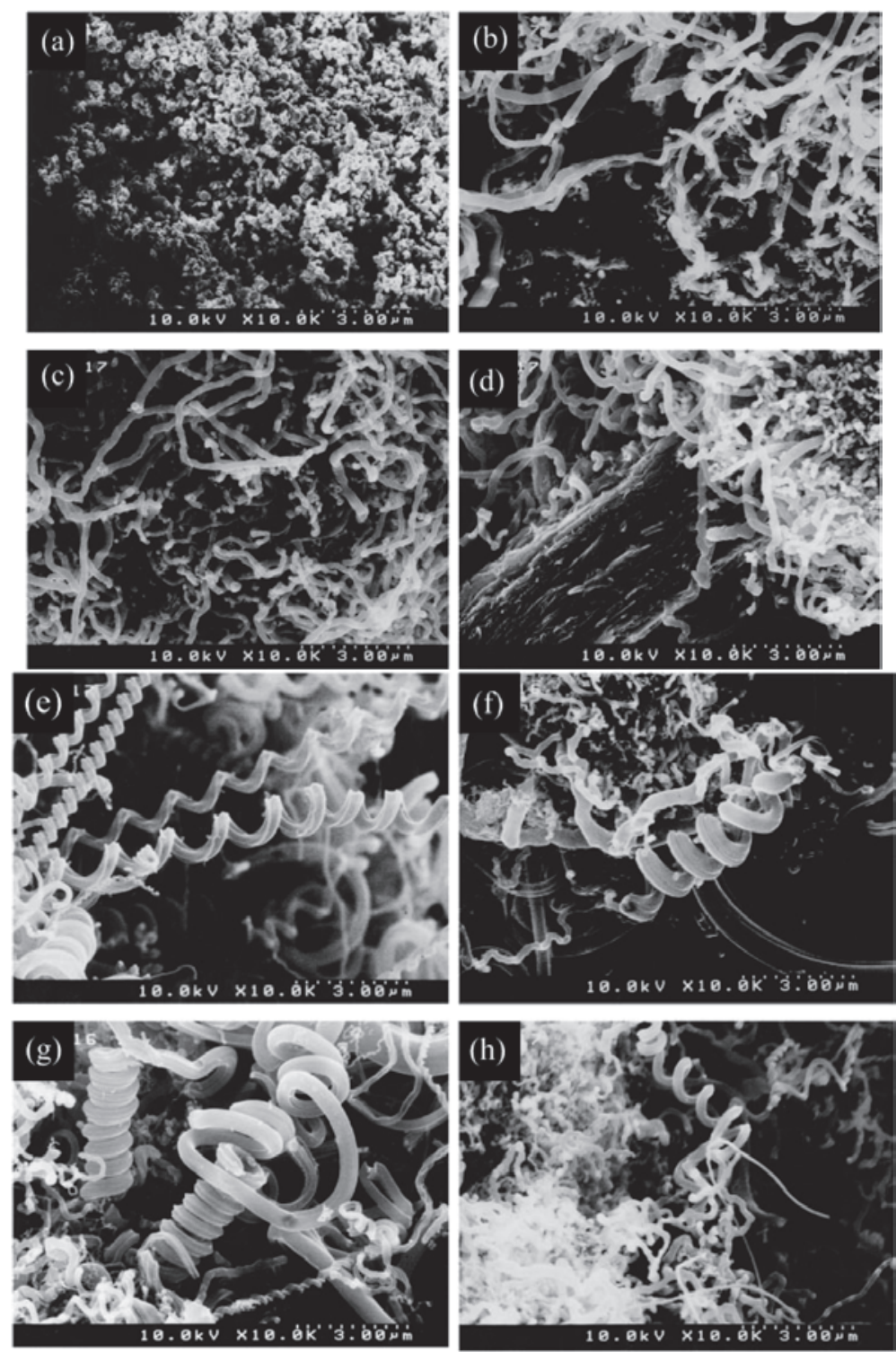

Fig. 4. SEM micrographs of carbon materials deposited on the catalysts with various weight percentage of Fe: (a) $20 \%$, (b) $40 \%$, (c) $50 \%$, (d) $60 \%$, (e) $67 \%$, (f) $70 \%$, (g) $80 \%$, and (h) $100 \%$ in the mixture with $\mathrm{SnO}_{2}$. The reaction conditions are the same as those in the case of Fig. 3. (Xu et al., 2005) 
Figure 8 shows the dependence of CNC selectivity on the partial pressure of the $\mathrm{C}_{2} \mathrm{H}_{2}$ gas in the gas mixture with He gas. Although data were greatly scattered, there exists a maximum for the selectivity of CNC between 0.16 and 0.24 . The average selectivity of CNC obtained under these optimum conditions is approximately $55 \%$.

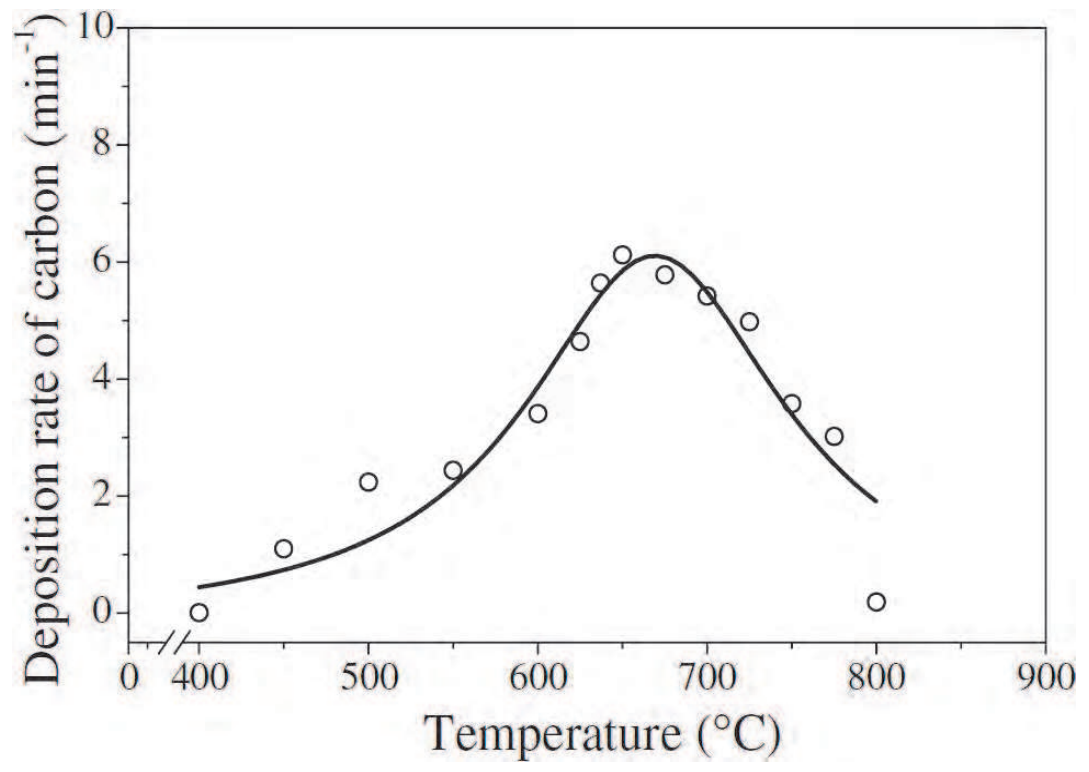

Fig. 5. Deposition rates of carbon materials at different reaction temperatures. Pyrolysis of $\mathrm{C}_{2} \mathrm{H}_{2}$ was carried out on $10 \mathrm{mg}$ mixture of $\mathrm{Fe}$ and $\mathrm{SnO}_{2}$ of 2 to 1 weight ratio for $10 \mathrm{~min}$ with the flow rates of $\mathrm{C}_{2} \mathrm{H}_{2}$ and $\mathrm{He}$ gases of 180 and $420 \mathrm{ml} / \mathrm{min}$, respectively. (Xu et al., 2005) 

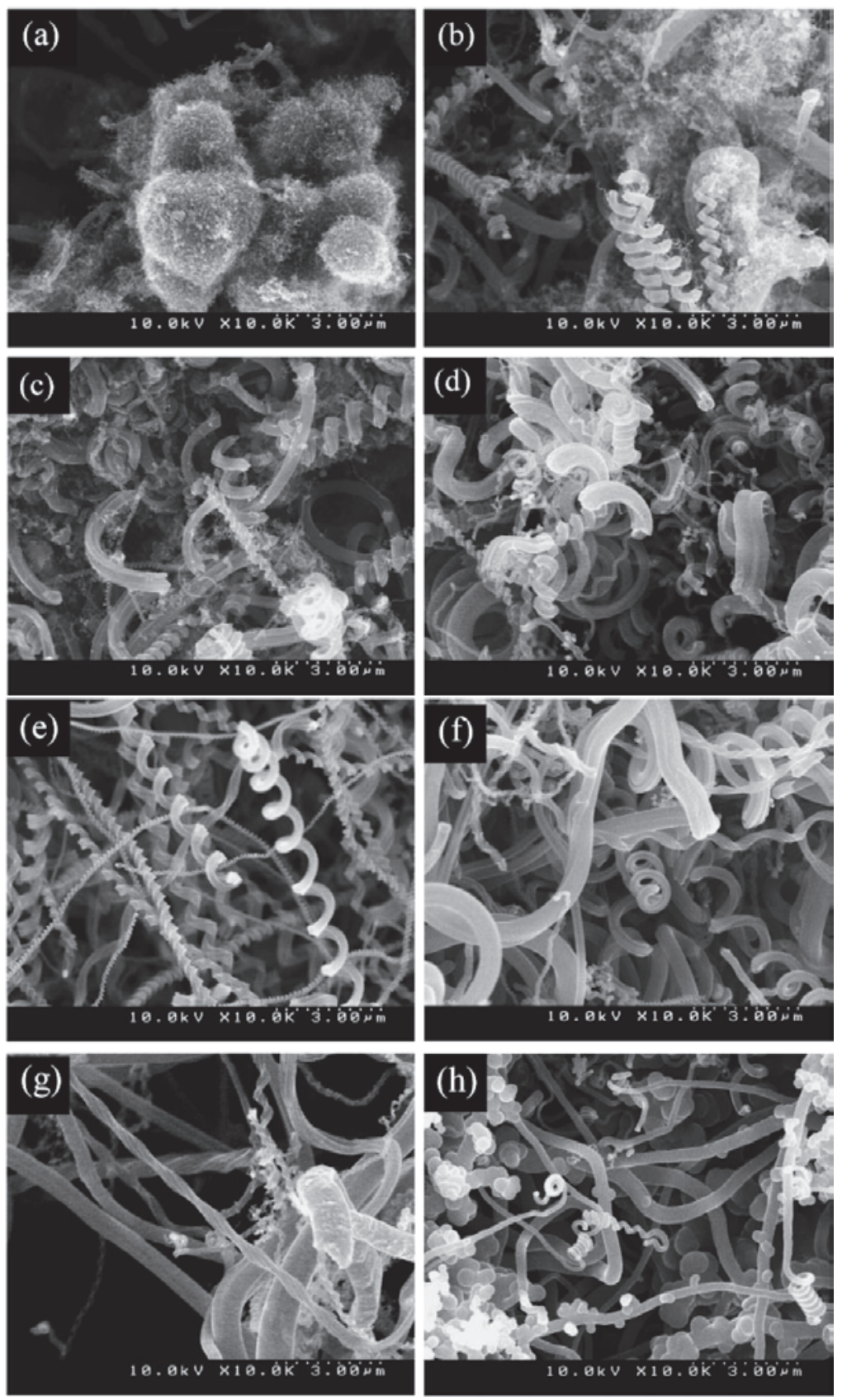

Fig. 6. SEM micrographs of the carbon materials deposited on the catalysts at the temperatures of (a) $500^{\circ} \mathrm{C}$, (b) $600^{\circ} \mathrm{C}$, (c) $650^{\circ} \mathrm{C}$, (d) $675^{\circ} \mathrm{C}$, (e) $700^{\circ} \mathrm{C}$, (f) $725^{\circ} \mathrm{C}$, (g) $750^{\circ} \mathrm{C}$, and (h) $800^{\circ} \mathrm{C}$. (Xu et al., 2005) 


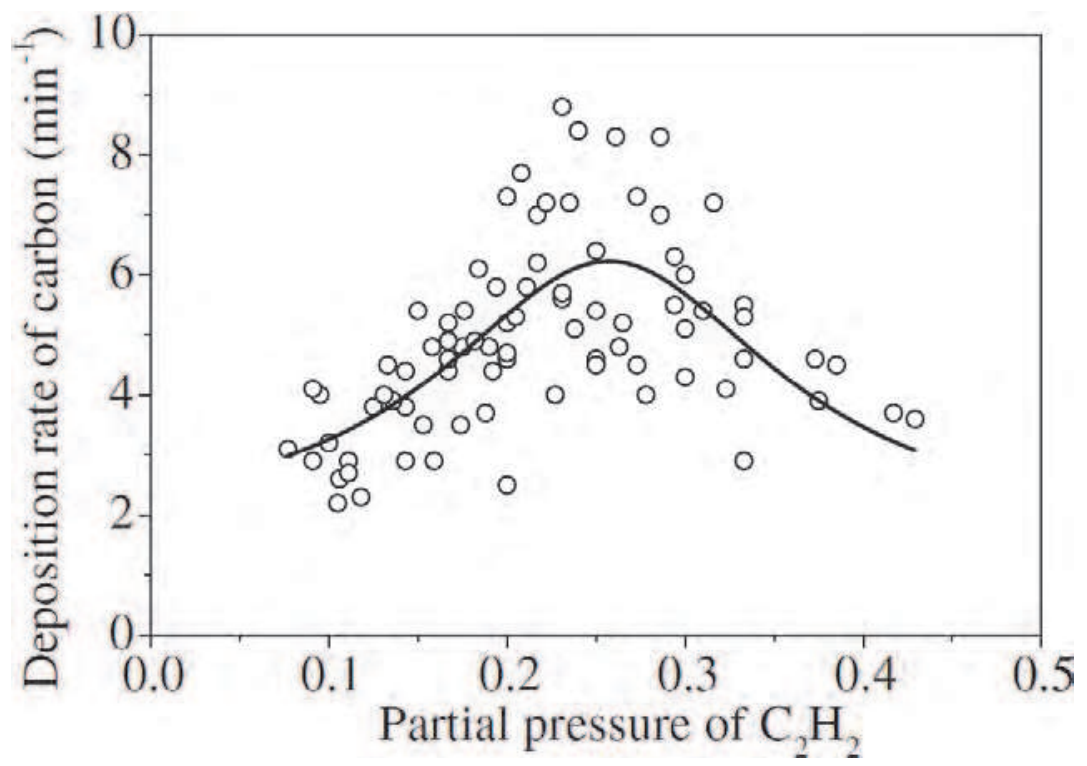

Fig. 7. Deposition rates of carbon materials at different reaction temperatures. Pyrolysis of $\mathrm{C}_{2} \mathrm{H}_{2}$ was carried out on $10 \mathrm{mg}$ mixture of $\mathrm{Fe}$ and $\mathrm{SnO}_{2}$ of 2 to 1 weight ratio for $10 \mathrm{~min}$ with the flow rates of $\mathrm{C}_{2} \mathrm{H}_{2}$ and $\mathrm{He}$ gases of 180 and $420 \mathrm{ml} / \mathrm{min}$, respectively. (Xu et al., 2005)

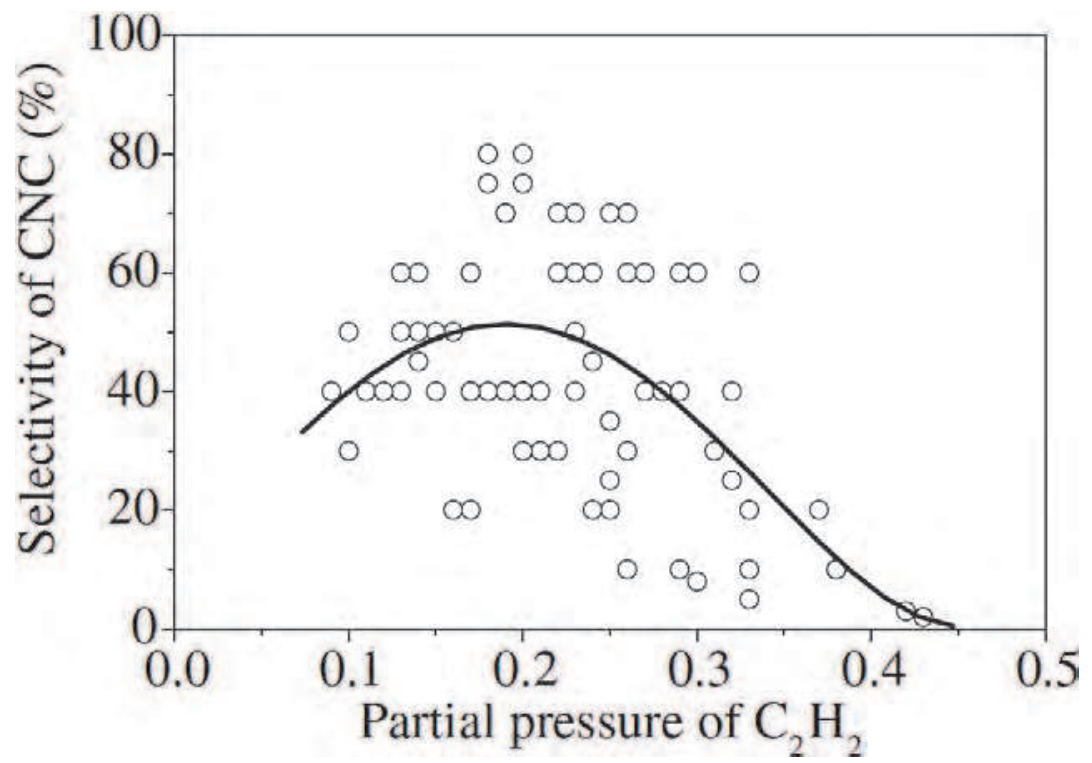

Fig. 8. Selectivity of CNCs plotted with partial pressure of $\mathrm{C}_{2} \mathrm{H}_{2}$ in a mixture with He gas. The process conditions are the same as those in the case of Fig. 7. (Xu et al., 2005) 

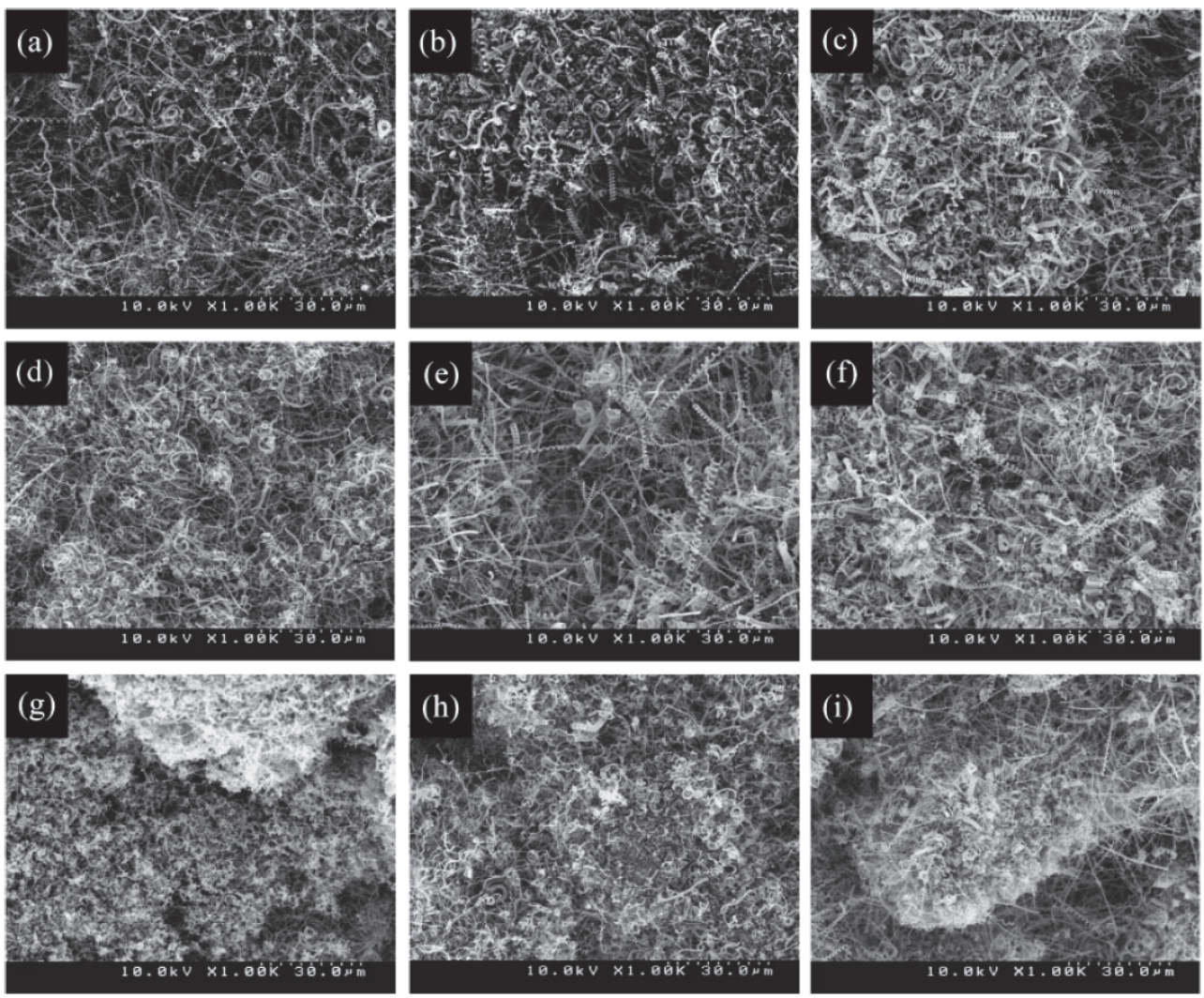

Fig. 9. SEM micrographs of the carbon deposited in $\mathrm{C}_{2} \mathrm{H}_{2} / \mathrm{He}$ gas mixtures of (a) 100/400, (b) 100/700, (c) 100/1000, (d) 150/400, (e) 150/700, (f) 150/1000, (g) 300/400, (h) 300/700, and (i) 300/1000. The CVD conditions are the same as those in Fig. 7. (Xu et al., 2005)
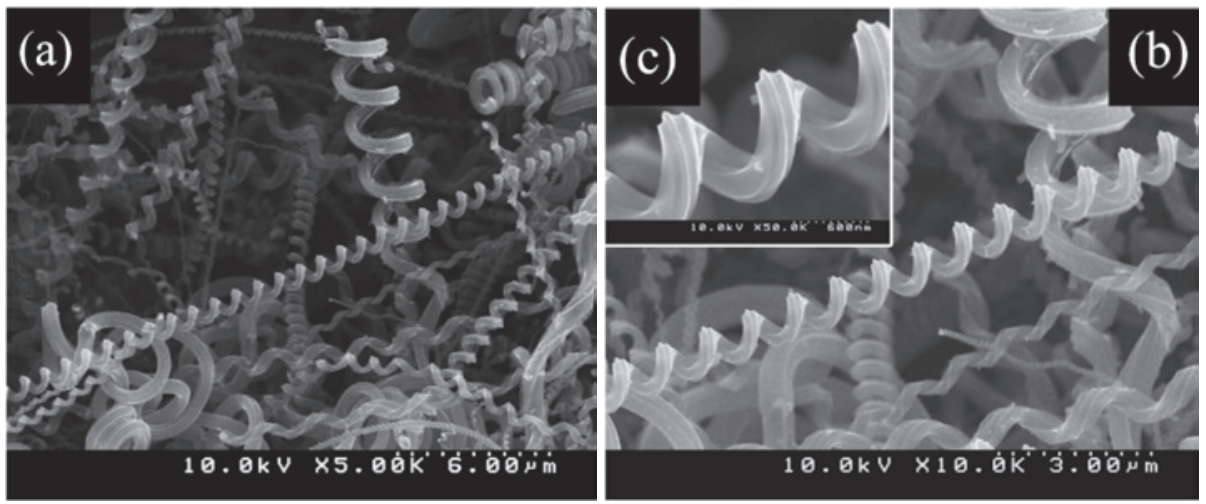

Fig. 10. SEM micrographs of carbon deposits under the optimum condition at (a) low, (b) middle and (c) high magnification. (Xu et al., 2005) 
Figure 9 shows SEM micrographs of carbon deposits at gas compositions of $100 \mathrm{ml} / \mathrm{min}$ $\mathrm{C}_{2} \mathrm{H}_{2}$ gas in the mixture with (a) 400, (b) 700, and (c) $1000 \mathrm{ml} / \mathrm{min} \mathrm{He}$, those of carbon deposits with $150 \mathrm{ml} / \mathrm{min}_{2} \mathrm{H}_{2}$ gas in the mixture with (d) 400, (e) 700, and (f) $1000 \mathrm{ml} / \mathrm{min}$ $\mathrm{He}$, and those of carbon deposits with $300 \mathrm{ml} / \mathrm{min}_{2} \mathrm{H}_{2}$ gas in the mixture with $(\mathrm{g}) 400$, (h) 700, and (i) $1000 \mathrm{ml} / \mathrm{min}$ He. Higher $\mathrm{CNC}$ selectivity is observed on the diagonal line from upper left (a) through (e) to the lower right (i), and their $\mathrm{C}_{2} \mathrm{H}_{2}$ gas partial pressures are 0.20 , 0.18 , and 0.23 , respectively. While keeping the flow of $\mathrm{C}_{2} \mathrm{H}_{2}$ gas at $100 \mathrm{ml} / \mathrm{min}$, increasing the flow of He gas up to 700 and $1000 \mathrm{ml} / \mathrm{min}$ leads to the formation of more fibres and

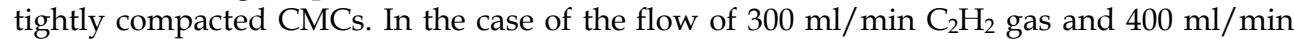
He gas, numerous carbon particles can be observed instead of CNCs, CNFs or CMCs.

\subsubsection{CNCs deposited under optimum conditions}

After systematical optimisation of process conditions to obtain high yield as well as high purity of $\mathrm{CNC}$, the best combination is confirmed to be $\mathrm{Fe} / \mathrm{SnO}_{2}$ catalyst of $2 / 1$ in weight, reaction temperature of $700^{\circ} \mathrm{C}$, and $\mathrm{C}_{2} \mathrm{H}_{2} / \mathrm{He}$ flow of $150 / 700 \mathrm{ml} / \mathrm{min}$. CNCs deposited under optimum conditions were characterised in detail with FE-SEM.

Under the optimum conditions, the average selectivity of CNCs is approximately $80 \%$, and the average deposition rate is approximately $5.5 \mathrm{~min}^{-1}$. Figure 10 shows SEM micrographs of CNCs deposited under the optimum condition. From the micrograph with lower magnification, CNCs with different pitches and diameters can be observed, the pitches for the same coil are almost the same, the axes of CNCs are quite straight, and the longest CNCs are over $50 \mu \mathrm{m}$. By measuring $200 \mathrm{CNCs}$ in the micrographs, the average pitch and diameter of the CNCs are found to be 750 and $750 \mathrm{~nm}$, respectively and the average diameter of CNC fibre is estimated to be $350 \mathrm{~nm}$.

\subsection{Parametric study on growth of carbon nanotwist}

In this section, parametric study on growth of carbon nanotwist (CNTw) reported by Katsumata et al. is introduced. The CVD apparatus with a NiCr alloy hot-filament was used to synthesize CNFs. Two methods were employed for preparing the catalyst-coated substrate. The first method was shielded cathodic arc deposition. (Takikawa et al., 1998) This method is a type of physical vapour deposition (PVD), in which the ions emitted from the cathode spot of vacuum arc discharge plasma are plated on the substrate. The second method was the sol-gel drop-coat method. Commercial sol-gel solutions for $\mathrm{NiO}$ and $\mathrm{CuO}$ coating, containing $3 \mathrm{wt} \%$ of $\mathrm{Ni}$ and $\mathrm{Cu}$, were ultrasonically mixed. Then the mixed solution was dropped from a pipette on the substrate and dried at $200^{\circ} \mathrm{C}$ on a hot plate.

\subsubsection{Ni/Cu multi-layer PVD-coated film catalyst}

In this experiment, the flow rate of the source gas was $180 \mathrm{ml} / \mathrm{min}$ and the process time was $20 \mathrm{~min}$. SEM and TEM micrographs of the deposited products under a different gas source and with/without hot-filament (HF) assist are shown in Figures 11 and 12, respectively.

When $\mathrm{C}_{2} \mathrm{H}_{2}$ gas was used without HF assist, as shown in Figures 11(a) and 12(a), CNC was synthesized. When $\mathrm{C}_{2} \mathrm{H}_{2}$ gas was used with HF assist, as shown in Figures 11(b) and 12(b), a rope-like fibre consisting of two to four fibres twisted together, called carbon nanorope (CNR), was synthesized. The CNR always had a catalyst particle at the top of the fibre. The TEM micrograph indicated the shape of the comparably fat trunk at the centre with thinner skin around the trunk. When $\mathrm{C}_{2} \mathrm{H}_{4}$ gas was used without HF assist, cocoon-like products 
were obtained, as shown in Figure 11(c). When $\mathrm{C}_{2} \mathrm{H}_{4}$ gas was used with $\mathrm{HF}$ assist, as shown in Figures 11(d) and 12(c), CNTw was synthesized. The outer diameters of CNC and CNTw were thinner than that of CNR. These results indicate that a Ni/Cu catalyst provides various shapes of HCNFs depending on process conditions.

Figure 13 shows the result of EDX analysis of CNTw. It was found that the major deposition material was $\mathrm{C}$, although the catalyst was composed of $\mathrm{Ni}$ and $\mathrm{Cu}$, with the amount of $\mathrm{Cu}$ in the catalyst higher than that of $\mathrm{Ni}$.

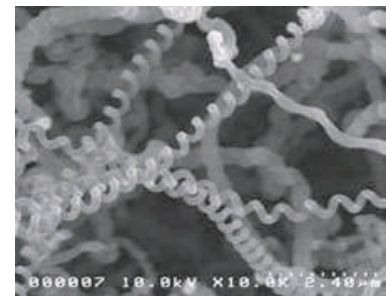

(a) $\mathrm{C}_{2} \mathrm{H}_{2}$ gas, without $\mathrm{HF}$ (carbon nanocoil, $\mathrm{CNC}$ )

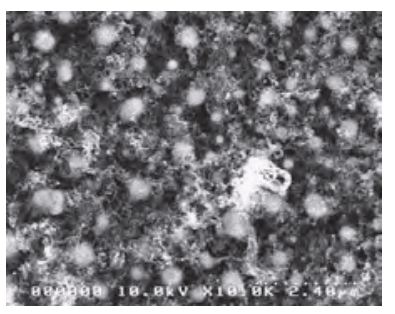

(c) $\mathrm{C}_{2} \mathrm{H}_{4}$ gas, without $\mathrm{HF}$

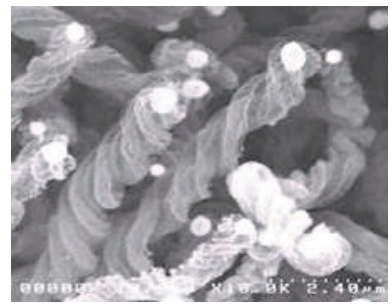

(b) $\mathrm{C}_{2} \mathrm{H}_{2}$ gas, with $\mathrm{HF}$ (carbon nanorope, CNR)

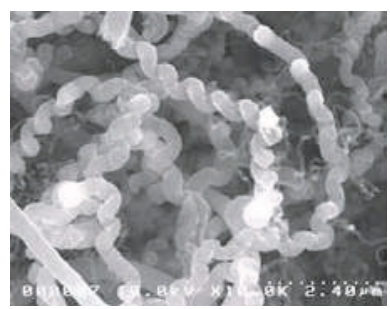

(d) $\mathrm{C}_{2} \mathrm{H}_{4}$ gas, with $\mathrm{HF}$ (carbon nanotwist, CNTw)

Fig. 11. SEM micrographs of various HCNFs prepared with Ni/Cu multi-layer PVD-coated film catalyst. HF: hot-filament assist. (Katsumata et al., 2004)

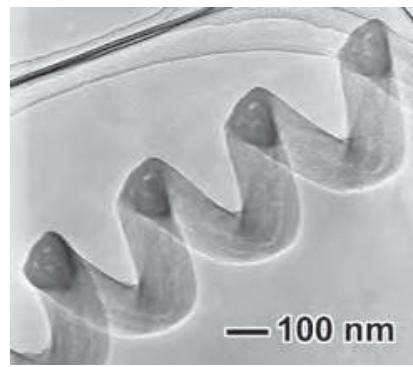

(a) $\mathrm{CNC}$

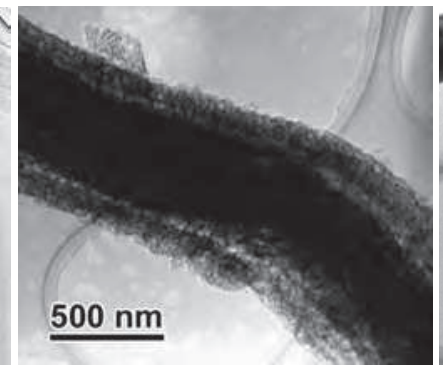

(b) CNR

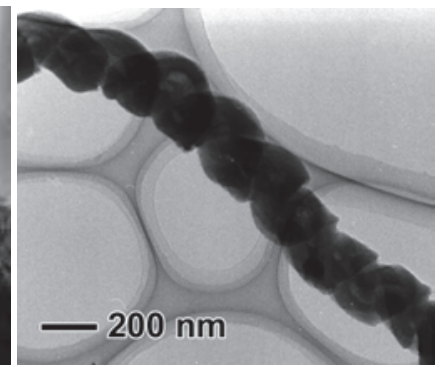

(c) $\mathrm{CNTw}$

Fig. 12. TEM micrographs of various HCNFs prepared with Ni/Cu multi-layer PVD-coated film catalyst. (Katsumata et al., 2004) 

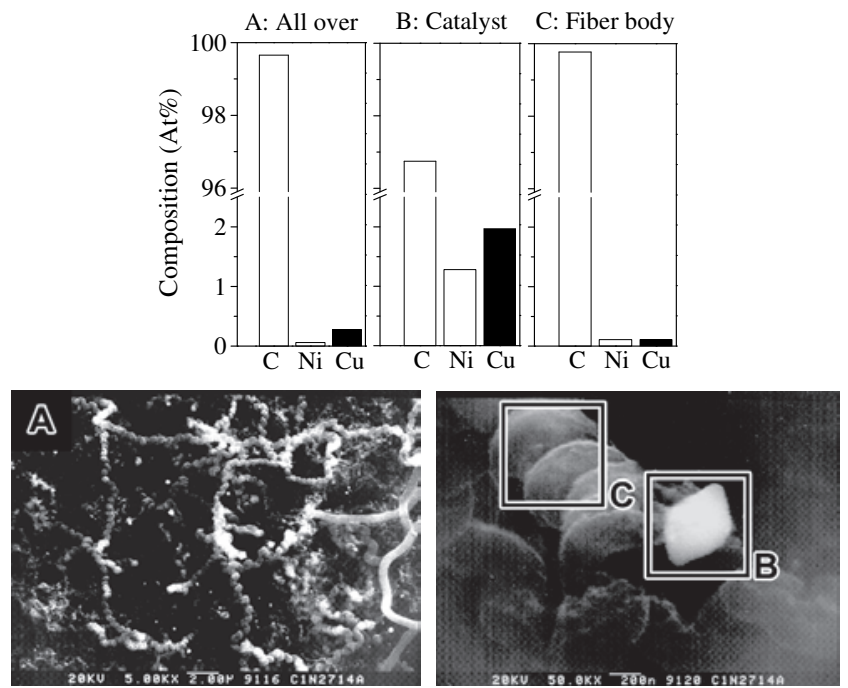

Fig. 13. EDX analysis of CNTw and SEM micrographs of analysis positions. (Katsumata et al., 2004).

\subsubsection{Ni/Cu mixture sol-gel film catalyst}

In this experiment, $\mathrm{C}_{2} \mathrm{H}_{2}$ gas was used as a carbon feedstock and a hot-filament was not used. The deposition time was $10 \mathrm{~min}$.

Figure 14 shows the dependence of the $\mathrm{NiO} / \mathrm{CuO}$ ratio on the carbon yield rate processed at $650^{\circ} \mathrm{C}$ with a $\mathrm{C}_{2} \mathrm{H}_{2}$ flow rate of $180 \mathrm{ml} / \mathrm{min}$. The range where the HCNF was obtained is indicated in the figure. When the amount of $\mathrm{NiO}$ was larger than that of $\mathrm{CuO}$, the deposition amount was larger, although the product was mostly CNFs without helicity. When the NiO amount was lower, the deposition amount was smaller and the product was mostly HCNFs. The optimum $\mathrm{NiO} / \mathrm{CuO}$ composition ratio for $\mathrm{HCNF}$ synthesis was in the range of $4 / 6-1 / 9$ and the optimum was $2 / 8$. This ratio is very close to a previous report indicating that the ratio of $\mathrm{Ni} / \mathrm{Cu}=3 / 7$ provides the $H C N F s$ in the CVD process with $\mathrm{C}_{2} \mathrm{H}_{4}$. (Kim et al., 1992)

Figure 15 shows the temperature dependence of the carbon yield rate. The $\mathrm{NiO} / \mathrm{CuO}$ ratio was $2 / 8$. When the temperature was $500-600^{\circ} \mathrm{C}$, which was the optimum, the HCNF product yield as well as the carbon yield rate was high, and the fibre diameter was $80-100 \mathrm{~nm}$. When the temperature was higher than $600^{\circ} \mathrm{C}$, the carbon yield was lower, the HCNF yield was low, and the HCNFs were thick (200-300 nm diameter). When the temperature was lower than $500^{\circ} \mathrm{C}$, the carbon yield was lower and the HCNF yield was low. The temperature obtained in the present work was lower than the optimum temperature of $600-700^{\circ} \mathrm{C}$ for $\mathrm{Ni} / \mathrm{Cu}$ catalyst and $\mathrm{C}_{2} \mathrm{H}_{4}$ feedstock gas. (Kim et al., 1992) This implies that $\mathrm{C}_{2} \mathrm{H}_{2}$, which is readily to thermally decomposed, is adequate for the lower temperature process.

The influence of the flow rate of the $\mathrm{C}_{2} \mathrm{H}_{2}$ source gas on the carbon yield rate is shown in Figure 16. When the $\mathrm{C}_{2} \mathrm{H}_{2}$ gas flow rate was lower than $100 \mathrm{ml} / \mathrm{min}$, carbon yield was low and the product was a CNF without helicity. When the flow rate was $125-180 \mathrm{ml} / \mathrm{min}$, the HCNF 
yield as well as the carbon yield rate was high. When the flow rate was higher, the carbon yield was also high though a HCNF was not obtained. In this experiment, most HCNFs grown were CNTw. Figure 17 is a micrograph of CNTws prepared in the optimum condition.

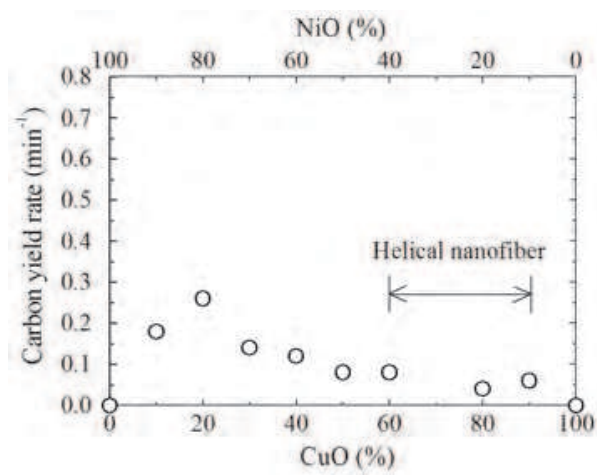

Fig. 14. Dependence of $\mathrm{NiO} / \mathrm{CuO}$ catalyst composition rate on carbon yield rate. Process temeperature, $650^{\circ} \mathrm{C} ; \mathrm{C}_{2} \mathrm{H}_{2}$ flow rate, $180 \mathrm{ml} / \mathrm{min}$. (Katsumata et al., 2004)

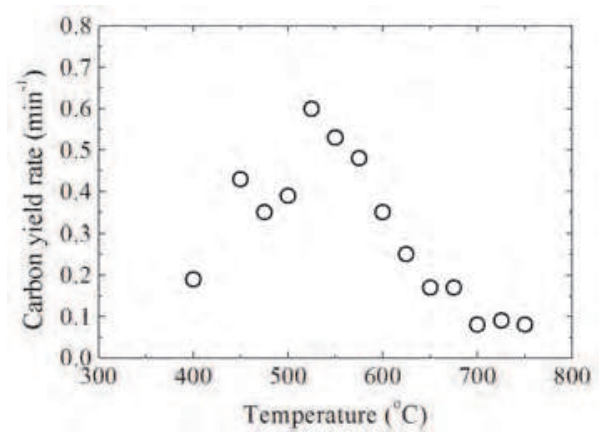

Fig. 15. Dependence of process temperature on carbon yield rate. $\mathrm{NiO} / \mathrm{CuO}$ ratio, $2 / 8 ; \mathrm{C}_{2} \mathrm{H}_{2}$ flow rate, $180 \mathrm{ml} / \mathrm{min}$. (Katsumata et al., 2004)

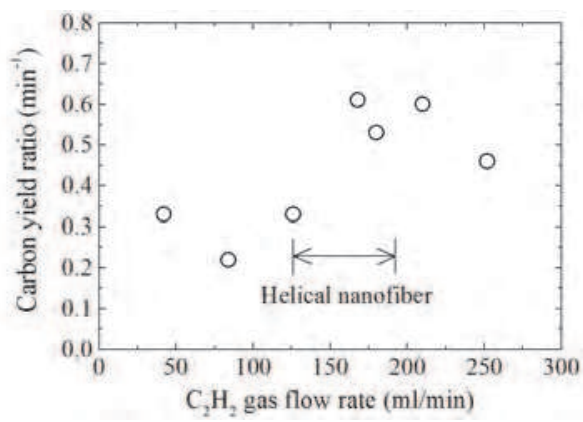

Fig. 16. Dependence of source gas flow rate on carbon yield rate. $\mathrm{NiO} / \mathrm{CuO}$ ratio, 2/8; process temperature, $550^{\circ} \mathrm{C}$. (Katsumata et al., 2004) 


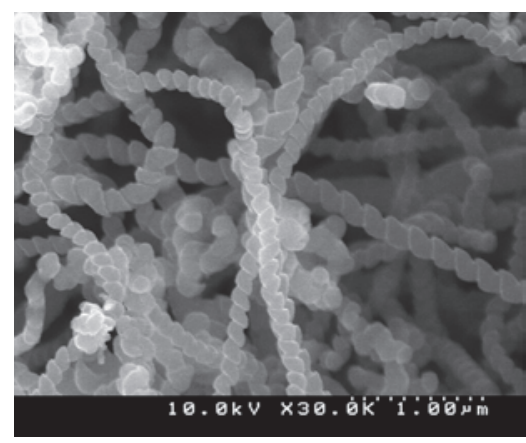

Fig. 17. $\mathrm{CNTw}$ obtained at optimum conditions. $\mathrm{NiO} / \mathrm{CuO}$ ratio, 2/8; process temperature, $550^{\circ} \mathrm{C} ; \mathrm{C}_{2} \mathrm{H}_{2}$ flow rate, $160 \mathrm{ml} / \mathrm{min}$. (Katsumata et al., 2004)

\subsection{Increase of the CNTw production rate by an automatic CVD system}

In this section, the results by an automatic CVD system that the production rate of CNTw increased up to 5400 times, compared with the conventional CVD system are shown. (Hosokawa et al., 2007) The automatic CVD system is described in detail in Section 4.2. The detail of CNTw growth conditions is indicated in each of the figure caption.

The synthesized carbon nanomaterials were observed by a compact digital camera and an FE-SEM, as shown in Figure 18. In case of the direct film-growth CNTw on Ti-coated glass, the CNTw yield in carbonaceous product was almost $100 \%$, and no other shape of carbonaceous material was found. The overview morphology of the film was quite uniform. The weight of the catalyst coated on the substrate was $0.7 \mathrm{mg}$. The film thickness was approximately $4 \mu \mathrm{m}$ for 30 -minute process time. The weight of the film was $1.3 \mathrm{mg}$, evaluated from the weight change of the substrate before and after CNTw growth. Thus, the

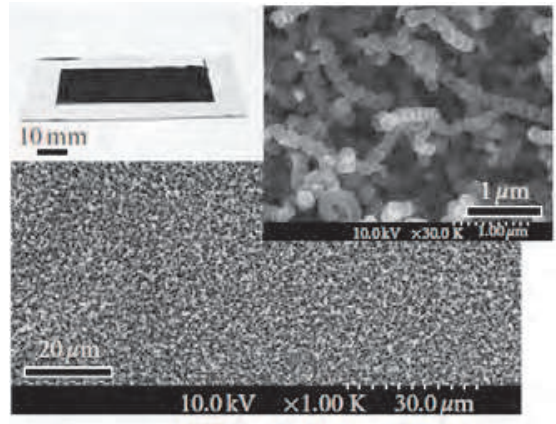

(a)

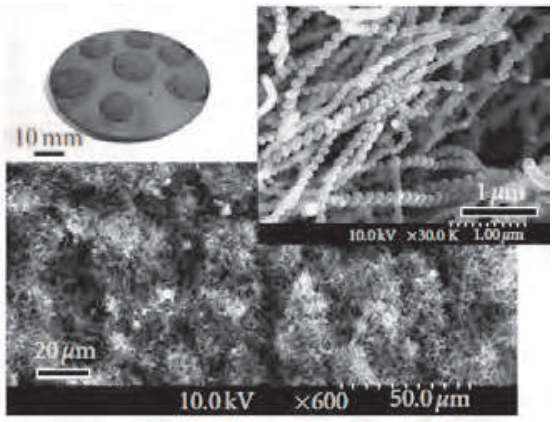

(b)

Fig. 18. Photograph and SEM micrograph of CNTw. (a) Direct film-growth of CNTw on Ticoated glass substrate. $\mathrm{Ni} / \mathrm{Cu} / \mathrm{In}_{2} \mathrm{O}_{3}$ catalyst was used. The flow rates of $\mathrm{C}_{2} \mathrm{H}_{2}: 80 \mathrm{ml} / \mathrm{min}$; He: $420 \mathrm{ml} / \mathrm{min}$; reaction temperature: $470^{\circ} \mathrm{C}$. (b) Powdery CNTw synthesized in automatic CVD system on graphite substrate. $\mathrm{Ni} / \mathrm{SnO}_{2}$ catalyst was used. The flow rates of $\mathrm{C}_{2} \mathrm{H}_{2}: 350 \mathrm{ml} / \mathrm{min}$; $\mathrm{N}_{2}: 1400 \mathrm{ml} / \mathrm{min}$; reaction temperature: $470^{\circ} \mathrm{C}$. Upper left, overall view; upper right, highmagnification SEM; lower, low-magnification SEM, respectively. (Hosokawa et al., 2007) 
synthesis ratio of CNTw against the catalyst in weight, indicating the production efficiency on catalyst, was approximately 1.9, and the production rate was approximately $0.5 \mathrm{mg} / \mathrm{h}$.

As shown in Figure 18(b), the product of CNTw synthesized from $\mathrm{Ni} / \mathrm{SnO}_{2}$ catalyst formed a softly-swollen dome shape on the substrate. So far, when 8 substrates were consecutively processed, approximately $6 \mathrm{~g}$ of CNTw was produced in 3 hours. In average, $900 \mathrm{mg}$ CNTw was produced on 1 substrate by $36 \mathrm{mg}$ of catalyst. Thus, the production rate was approximately $2,700 \mathrm{mg} / \mathrm{h}$, and productivity of powdery CNTw was 5,400 times, compared with direct film-growth. The grown CNTw was easily scraped off the substrate and the powdery form CNTw was obtained. Yield of CNTw shape material in the carbonaceous product was almost $100 \%$. The synthesis ratio of CNTw against the catalyst in weight was approximately 25 . The fibre diameter of powdery CNTw was found to be thinner (average $90 \mathrm{~nm}$ ) than that of the direct film growth CNTw (average $150 \mathrm{~nm}$ ).

\section{Analyses of HCNFs structure and their growth mechanism}

\subsection{Splitting and flattening of HCNFs}

In this section, the experimental result that $\mathrm{CNC}$ was found to show a drastic shape change, splitting and flattening when HCNFs were acidified in a $30 \%$ hydrogen peroxide solution. (Yokota et al., 2010) The HCNF growth condition is indicated in each of the figure caption.

\subsubsection{Experimental details}

HCNFs were prepared with a CVD system, as previously reported. (Takikawa et al., 2000), (Katsumata et al., 2004) The substrate was a graphite plate $(25 \times 25 \mathrm{~mm}$, thickness $3 \mathrm{~mm})$ placed at the reactor centre. A liquid-state mixed catalyst was dropped on to the substrate, then dried to solidify at $200^{\circ} \mathrm{C}$ for $10 \mathrm{~min}$ in air and the $\mathrm{Fe} / \mathrm{Sn}$ or Ni/Sn catalyst was formed. The source gas used was $\mathrm{C}_{2} \mathrm{H}_{2}(150 \mathrm{ml} / \mathrm{min})$ and the dilute gas was $\mathrm{N}_{2}(1000 \mathrm{ml} / \mathrm{min})$. The other conditions were as follows: the reaction temperature was $700^{\circ} \mathrm{C}(\mathrm{Xu}$ et al., 2005) using the $\mathrm{Fe} / \mathrm{Sn}$ catalyst for $\mathrm{CNC}$ synthesis and $550^{\circ} \mathrm{C}$ using the $\mathrm{Ni} / \mathrm{Sn}$ catalyst for CNTw synthesis. The growth time was $10 \mathrm{~min}$ for each reaction.

$50 \mathrm{mg}$ of as-prepared HCNF was treated in a flask with $10 \mathrm{ml}$ of a $30 \%$ hydrogen peroxide solution under reflux. The treatment temperature was varied from 20 to $200^{\circ} \mathrm{C}$ for $1 \mathrm{~h}$. The treatment time was $30-150 \mathrm{~min}$ at $100^{\circ} \mathrm{C}$ and $15-90 \mathrm{~min}$ at $140^{\circ} \mathrm{C}$. After the treatment, the acid-treated HCNF was extracted from the solution by suction filtration and subsequently dried at $120^{\circ} \mathrm{C}$ for $1 \mathrm{~h}$ on a hotplate.

\subsubsection{Synthesis of HCNFs acid-treated}

Figure 19 shows the surface images of as-prepared CNCs and CNTws. By careful observation, as-prepared CNCs and CNTws were found to be categorized into angular- and round-types according to their fibre cross-sections (see Figure 1). The Ni-Sn catalyzed reaction produces only the round-type CNTw. However, the Fe-Sn catalyzed reaction produces the other three types simultaneously; round and angular-type CNCs and the angular-type CNTw. The typical yield of CNCs in the products prepared using the Fe-Sn catalyst was $30-40 \%$ as determined from the SEM observations. The content ratio of HCNFs was $>90 \%,<10 \%$ and $<1 \%$ for the angular-type CNCs, angular-type CNTws and round type CNCs, respectively. 


\subsubsection{Acid treatment results}

SEM micrographs of the four types of CNCs and CNTws after acid treatment are shown in Figure 20. The shape of the angular-type $\mathrm{CNC}$ was found to change dramatically. While the angular-type CNC was split and flattened, the round-type CNC was also split but not significantly flattened. As for the angular-type $\mathrm{CNTw}$, the fibre surface was slightly edged. The shape of the round-type CNTw was unaffected by the treatment.

The weight loss and shape change of CNCs by acid treatment for $1 \mathrm{~h}$ were evaluated. (Yokota et al., 2010) The weight decreased as the temperature was increased. Furthermore, the weight decreased dramatically at $80-120^{\circ} \mathrm{C}$. The weight loss was due to the carbon oxidation reaction. The release of carbon dioxide was confirmed by the observation that limewater became cloudy by the gas generated during the acid treatment. Therefore, these results indicate that etching of CNCs and dissolution of amorphous carbon progressed when the oxidation reaction proceeded at temperatures above $80^{\circ} \mathrm{C}$. The saturation of weight loss was observed over $140^{\circ} \mathrm{C}$ and this was caused by the boiling of the hydrogen peroxide solution (i.e., boiling point of $141^{\circ} \mathrm{C}$ ). The $\mathrm{CNC}$ shape did not change between 20 and $60^{\circ} \mathrm{C}$. CNCs were split into a few pieces over $100^{\circ} \mathrm{C}$. The weight loss as a function of treatment time for reaction temperatures of 100 and $140^{\circ} \mathrm{C}$ was also evaluated. (Yokota et al., 2010) As the treatment time increased, the shape change became significant. The weight loss reached saturation at $100^{\circ} \mathrm{C}$ when the reaction time was $>120 \mathrm{~min}$, whereas at $140^{\circ} \mathrm{C}$, saturation was reached after $45 \mathrm{~min}$. At saturation, the weight difference due to the different temperatures was $\sim 48 \%$ at $100^{\circ} \mathrm{C}$ and $\sim 38 \%$ at $140^{\circ} \mathrm{C}$.

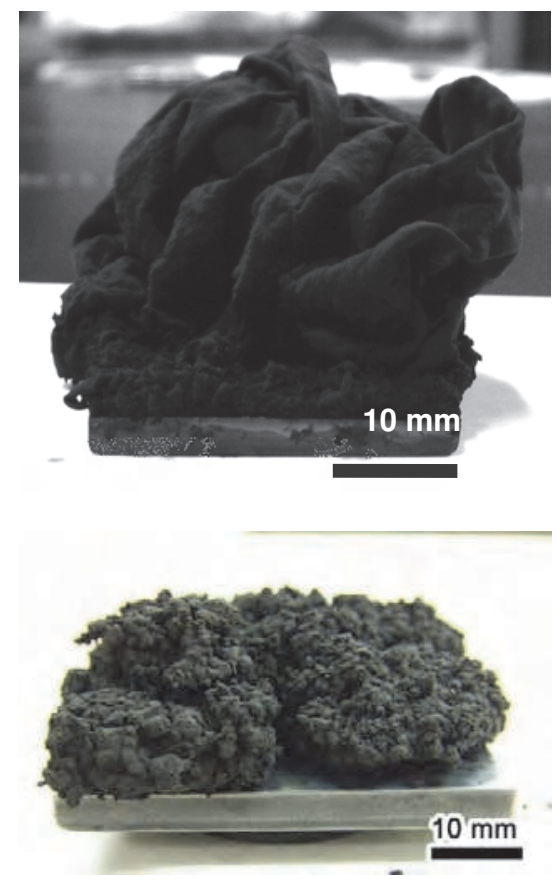

Fig. 19. Images of as-grown HCNFs synthesized by CVD. (a) CNCs using the Fe/Sn catalyst and (b) CNTws using the Fe/Sn catalyst. 

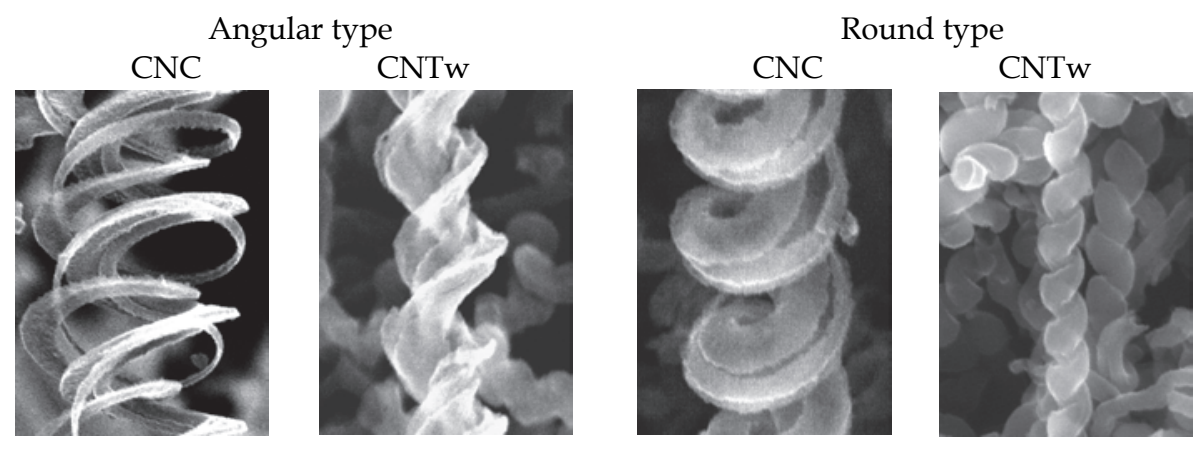

Fig. 20. SEM micrographs of four types of HCNFs after the acid treatment.

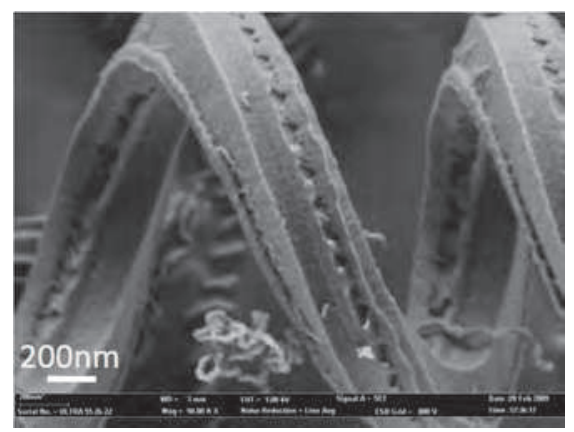

Fig. 21. SEM micrograph of CNC by the FE-SEM with a low acceleration voltage. Courtesy of Dr. Hamanaka at JFCC.

As previously described, the structures of most HCNFs prepared with an Fe-based catalyst are not uniform in the radial direction of the fibre. (Chen et al., 2004), (Xu et al., 2005), (Zhang et al., 2000), (Pan et al., 2002), (Yang et al., 2005) In other words, there are high and low density regions inside the fibre. Figure 21 shows a micrograph of angular-type CNC by the FE-SEM with a low acceleration voltage. Difference in the surface structure of CNC is clearly observed. This non-uniformity continues along the length of the fibre. The low density part, which is bonded to the high density parts, is considered to initially dissolve by acid treatment while the high density parts remain and appear as flattened CNCs.

\subsection{Analysis of the CNC structure by 3D-TEM}

To analyse the CNC structure, electron tomography of the as-grown and acid-treated CNCs was obtained using a TEM tomography system (JEOL, TEMography). (Yokota et al., 2010) The TEM images of the samples were serially recorded at tilt angles from 60 to $-60^{\circ}$ degrees with a $1^{\circ}$ step size (i.e., total of 120 images). The CNC position in each image was aligned precisely.

Figure 22 shows a TEM micrograph of $\mathrm{CNC}$ before acid treatment. The transmission image of an as-grown $\mathrm{CNC}$ showed contrasting density in the fibre. In contrast, the flattened CNC after acid treatment showed a uniform contrast. An SEM observation showed that the 
number of the fibres after acid treatment was dependent on the $\mathrm{CNC}$ shape. Figure 23 shows that the CNC split into three fibres.

The 3D image of CNCs was taken by electron tomography. The cross-sectional image showed that there is a shadow present inside the CNCs. This shadow was seen from the images sliced in the $x, y$ and $z$ directions. This shadow indicates the existence of a cavity inside the CNC. These results show that the structure of the CNC has a hollow centre. The flattened $\mathrm{CNC}$ after acid treatment showed that three helical fibres were in parallel. The cross-sectional observation showed that each fibre was separated and their diameter was approximately a quarter of the as-grown $\mathrm{CNC}$.

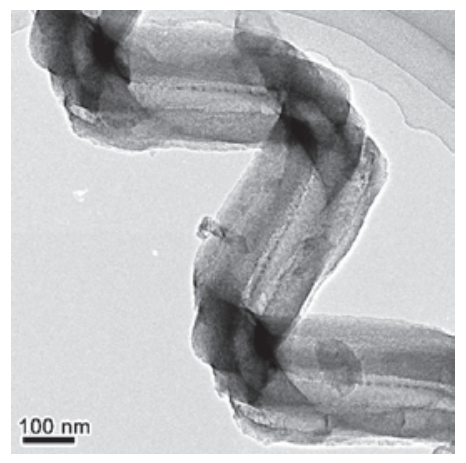

Fig. 22. TEM micrograph of as-grown CNC.

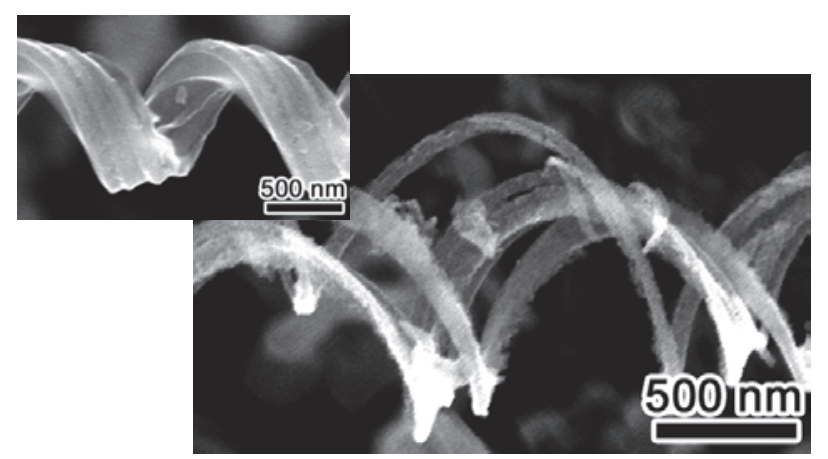

Fig. 23. The CNC splits into three fibres.

\subsection{HCNFs growth mechanism}

\subsubsection{General mechanism for growth of carbon fibres}

Baker et al. postulated a bulk-diffusion model of carbon through catalyst particles. (Baker et al., 1972) In this mechanism, hydrocarbon gas decomposes on exposed surfaces of catalyst particles into hydrogen and carbon. Because this reaction is exothermic, a temperature gradient is believed to exist through a catalyst particle. The dissociated carbon dissolves into the surface of the heated catalyst particle and diffuses to its cold tail. Since the solubility of carbon in a catalyst particle is temperature dependent, excess carbon precipitates out to 
form carbon filaments with the same diameter as that of the catalyst particle. The bulk diffusion is believed to be the limiting step of the process.

Another model of CNF formation has been demonstrated by Rodriguez et al. (Rodriguez, 1993), (Rodriguez et al., 1995) In this model, catalyst particles are characterised as tiny crystals with various facets. Hydrocarbon decomposes at one face, and carbon in the form of a graphite layer precipitates at another face. Catalyst composition and crystallinity dominate the structure of deposited fibres. For example, herringbone structure was formed from $\mathrm{Fe}-$ $\mathrm{Cu}(7 / 3)$ catalyst in $\mathrm{C}_{2} \mathrm{H}_{4}-\mathrm{H}_{2}(4 / 1)$ gas mixture, whereas the stacked structure was predominant due to the reaction of $\mathrm{CO}-\mathrm{H}_{2}(4 / 1)$ on Fe-based catalyst. Hydrogen is important in CNF formation, because it acts as the terminator of dangling bonds at edges of stacked graphite platelets. (Nolan et al., 1995) The concept of a spatial velocity was introduced to explain the growth of wavy and helical nanotubes. The mismatch between extrusion velocities of different faces of a catalyst particle results in the deformation of carbon deposits. (Fonseca et al., 1996), (Fonseca et al., 1995), (Amelinckx et al., 1994)

In spite of the differences between these models, it is commonly accepted that hydrocarbon precursors dissociate on catalyst particles, and the formed carbon species dissolve into catalyst particles and recombine to form carbon filaments. This general mechanism suggests that the fibre diameter is dominated by the particle size of the catalyst, the carbon structure is determined by the crystallinity of the catalyst, and the filament shapes, such as tubular, helical, or wavy, are related to the surface anisotropy or composition of the catalyst.

\subsubsection{Interpretation of temperature effects}

Generally, below room temperature, acetylene is adsorbed molecularly with its C-C axis parallel to the catalyst surface. (Hung \& Bernasek, 1995) The thermal pyrolysis may follow several routes depending on the initial coverage and catalyst activity. Acetylene adsorbs on a clean $\mathrm{Fe}(100)$ surface by $\mathrm{sp}^{3}$ hybridization. At lower exposure $(<0.2$ layer $), \mathrm{C}_{2} \mathrm{H}_{2}$ decomposes to form $\mathrm{CH}$ and $\mathrm{CCH}$ at $-20^{\circ} \mathrm{C}$. At higher exposure ( $>0.2$ layer), $\mathrm{C}_{2} \mathrm{H}_{2}$ partially dehydrogenates to form $\mathrm{CH}, \mathrm{CCH}$ and $\mathrm{CHCH}_{2}$ at the adsorption temperature of $-173^{\circ} \mathrm{C}$. When the surface is warmed to $120^{\circ} \mathrm{C}$, a $\mathrm{CCH}_{2}$ species is formed by the dehydrogenation of $\mathrm{CHCH}_{2}$. (Hung \& Bernasek, 1995) This means that acetylene adsorption on $\mathrm{Fe}$ is a self-initiative process and the activation energy of $\mathrm{C}_{2} \mathrm{H}_{2}$ decomposition is fairly low. However, at high temperature, $\mathrm{C}_{2} \mathrm{H}_{2}$ adsorption will result in a rather low coverage on catalyst.

In the kinetic study of the growth of CNTs on $\gamma$-Fe metal from acetylene, the activation energy was deduced, from an Arrhenius plot, to be $142 \mathrm{~kJ} / \mathrm{mol}$. (Baker, 1989) This value is close to the activation energy for carbon diffusion in bulk metal, $148 \mathrm{~kJ} / \mathrm{mol}$. (Smithells, 1992) This suggests that the bulk diffusion of carbon would be the rate-limiting step. (Lee et al., 2003) Since the solubility of carbon in a metal is also temperature dependent, temperature elevation will accumulate the dissolution as well as the diffusion of carbon in the catalyst particles. Therefore, an enhanced deposition rate of carbon is to be expected.

Unfortunately, the experimental results do not coincide with the above prediction. There must have been other factors affected by temperature. These factors include hydrocarbon adsorption on the catalyst, catalyst deactivation, and gas phase reactions of hydrocarbon. Since adsorption, pyrolysis of $\mathrm{C}_{2} \mathrm{H}_{2}$, and precipitation of carbon are all exothermic processes, (Bell \& Shustorovich, 1990) the increase of temperature shifts the reaction equilibrium to the precursor side and results in less total conversion. 
The optimum temperature for both the selectivity and the deposition rate of CNCs is around $700^{\circ} \mathrm{C}$ under the given experimental conditions. Noting that the eutectic point where austenite, ferrite and cementite coexist in the $\mathrm{Fe}-\mathrm{C}$ phase diagram is at $723^{\circ} \mathrm{C}$, phase changes accompanying transportation and precipitation of carbon is postulated to be a key in carbon fibre formation. (Qin, 1997)

\subsubsection{Mechanism involving gas reaction}

When hydrogen was used as the dilution gas in the pyrolysis of methane in an inductively coupled plasma reactor, CNFs were produced. However, replacing hydrogen with argon favours the production of MWCNTs. (Delzeit et al., 2002) Atomic hydrogen as well as hydrogen molecule acts as a terminator of dangling bonds on the edges of graphite platelets. Furthermore, because of the reaction of hydrogen with the carbon deposit, hydrogen is also believed to be helpful for avoiding the deactivation of the catalyst.

$\mathrm{Xu}$ and Pacey decomposed acetylene in a flow system between 584 and $697^{\circ} \mathrm{C}$ under pressures between 27 and 127 Torr. An induction period for the formation of vinylacetylene and benzene was observed, which was considered to be crucial evidence of a free radical mechanism. (Xu and Pacey, 2001) Although they suggested that two $\mathrm{C}_{2} \mathrm{H}_{2}$ molecules were involved in the initial reaction, collisions between $\mathrm{C}_{2} \mathrm{H}_{2}$ and He are considered to be the main happening in our system because of the high addition of a large amount of He gas.

\section{Synthesis of multi-walled CNC (MWCNC)}

In this section, the experimental result that thin $\mathrm{CNC}$ with a fibre diameter of $<50 \mathrm{~nm}$ was synthesized by CVD using Fe/Sn catalyst supported on zeolite is introduced. (Yokota et al., 2011) TEM observation revealed that more than $90 \%$ of the CNCs obtained were multiwalled CNCs (MWCNCs), and the remainder was columnar CNCs without a hollow structure. Three-dimensional images of an MWCNC with Au nanoparticles on its surface were reconstructed by electron tomography and confirmed that the MWCNC had a threedimensional helical shape. The HCNF growth condition is indicated in each of the figure caption.

\subsection{Experimental details}

Thin CNCs were synthesized using a catalytic CVD method and Fe/Sn catalyst supported on Y-type zeolite (Tosoh, HSZ-390HUA). The process of supporting metals on zeolite is as follows. Fe and Sn powders with a weight ratio of 3/2 were dissolved in dilute hydrochloric acid solution and mixed with the zeolite powder in the solution. The total weight of Fe and $\mathrm{Sn}$ in the solution was $5 \mathrm{wt} \%$. The mixed solution was then sonicated for $10 \mathrm{~min}$ and dried at $110^{\circ} \mathrm{C}$ for $20 \mathrm{~h}$. A $10 \mathrm{mg}$ quantity of the zeolite with $\mathrm{Fe} / \mathrm{Sn}$ catalyst on a quartz boat was placed in a quartz reactor tube. The tube was substituted with $\mathrm{N}_{2}(1000 \mathrm{ml} / \mathrm{min})$ and heated to desired reaction temperatures $\left(650-750^{\circ} \mathrm{C}\right)$ for $1 \mathrm{~h}$. When the reactor reached the desired temperature, $\mathrm{C}_{2} \mathrm{H}_{2}$ gas was added in the tube as a source gas for $10 \mathrm{~min}$ while keeping the $\mathrm{N}_{2}$ flow. The flow rate of $\mathrm{C}_{2} \mathrm{H}_{2}$ was varied between 50 and $300 \mathrm{ml} / \mathrm{min}$.

\subsection{SEM and TEM observation of MWCNCs}

Figure 24 shows SEM micrographs of zeolite with carbon fibres synthesized by CVD at $700^{\circ} \mathrm{C}$. The flow rates of $\mathrm{C}_{2} \mathrm{H}_{2}$ were (a) $50 \mathrm{ml} / \mathrm{min}$ and (b) $150 \mathrm{ml} / \mathrm{min}$, respectively. The 
CNC fibre diameters obtained by $\mathrm{C}_{2} \mathrm{H}_{2}$ flow rates of $50 \mathrm{ml} / \mathrm{min}$ and $150 \mathrm{ml} / \mathrm{min}$ were measured to be $\approx 20$ and $\approx 30 \mathrm{~nm}$, respectively. It seems that the fibre diameter thickened with increasing $\mathrm{C}_{2} \mathrm{H}_{2}$ flow rate. The fibre cross-section of thin $\mathrm{CNCs}$ is round without angles and differs from that of previously obtained CNCs synthesized by Fe microparticles with Sn solution, which had a reported fibre diameter of at least $120 \mathrm{~nm}$. (Zhang et al., 2000), (Yokota et al., 2010) Fe/Sn catalyst nanoparticles were formed on zeolite which has a mesoporous structure with pore size of $0.4-0.8 \mathrm{~nm}$. CNCs were observed only on the zeolite surface. It seems reasonable that the $\mathrm{Fe} / \mathrm{Sn}$ nanoparticle on zeolite synthesized the thin CNC.

Figure 25 shows TEM micrographs of thin CNCs synthesized with $50 \mathrm{ml} / \mathrm{min}_{2} \mathrm{H}_{2}$ flow. More than $90 \%$ of the thin CNCs obtained were multi-walled CNCs (MWCNCs). The striped pattern of the multiple layers and the hollow structure were observed clearly. Bamboo-like CNCs having a graphitic layer in the hollow and MWCNCs containing a nanoparticle in the hollow were observed. The particle encapsulated in an MWCNC was confirmed to be an Fe nanoparticle without Sn using an EDX spectroscope equipped with a TEM. Columnar CNCs that did not have hollows but having diameters almost the same as that of the MWCNCs were also observed. The number of MWCNCs, bamboo-like MWCNCs, nanoparticle-containing MWCNCs and columnar CNCs were 21, 2, 3 and 3 respectively in the sample. In addition, the coil diameter of columnar CNCs was smaller than that of the MWCNCs, indicating that the form of columnar CNCs resembles that of CNTw. (Hosokawa et al., 2008), (Yokota et al., 2010), (Takikawa et al., 2000) To our knowledge, the columnar $\mathrm{CNCs}$ have not been previously reported though there are reports of MWCNCs. (Kanada et al., 2008), (Lu et al., 2004), (Yang et al., 2003)
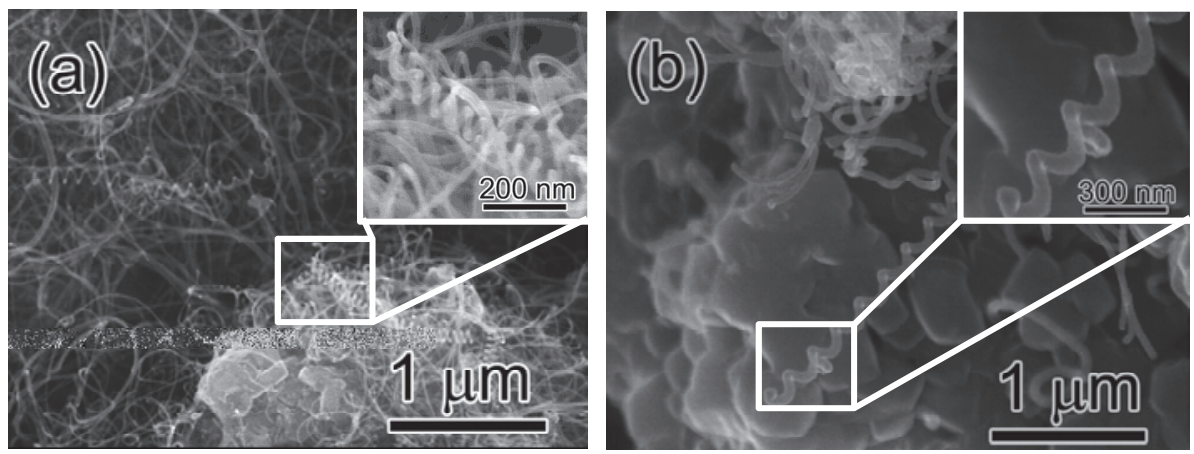

Fig. 24. SEM micrographs of thin CNCs synthesized by Fe/Sn catalyst supported on zeolite at $700^{\circ} \mathrm{C} \cdot \mathrm{C}_{2} \mathrm{H}_{2}$ flow rates were (a) 50 and (b) $150 \mathrm{ml} / \mathrm{min}$. 

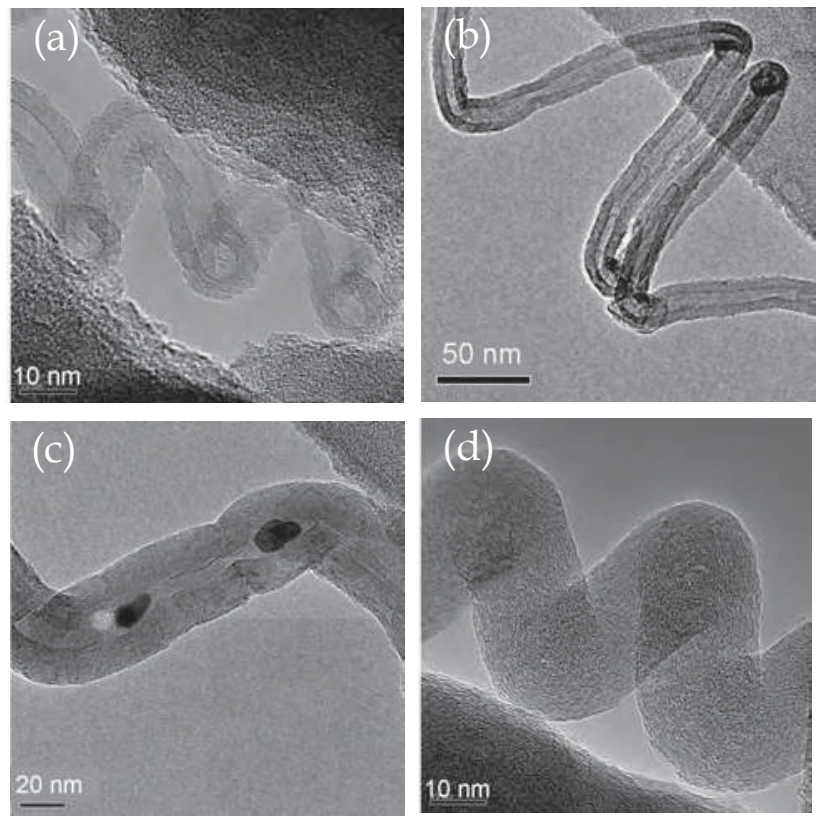

Fig. 25. TEM micrographs of thin CNCs. (a) A MWCNC with hollow and graphitic layer structures. (b) Bamboo-like CNC. (c) CNC containing an Fe nanoparticle in the tube. (d) Columnar CNC. The columnar CNC included concentric graphitic layers with spacing of $\approx 0.34 \mathrm{~nm}$. (Yokota et al., 2011)

The fibre and coil diameters of thin CNCs were measured from the TEM micrographs. The coil diameter is determined as the outer diameter of the CNC. The number of samples analysed was 29, and coil diameters could be measured for 23 of the 29 CNCs. The average fibre and coil diameters of thin CNCs were $15 \pm 5 \mathrm{~nm}$ and $50 \pm 20 \mathrm{~nm}$, respectively.

Kanada et al. reported that the fibre diameters of MWCNCs were less than $25 \mathrm{~nm}$ and the coil diameter was $54 \pm 20 \mathrm{~nm}$. (Kanada et al., 2008) These dimensions are similar to our results. The number of graphitic layers of MWCNCs and coil pitches were evaluated to be 10-30 and 25-200 nm, respectively. The fibre and coil diameters of the thin CNCs in this study were as small as 1/10 those for previously obtained CNCs. (Yokota et al., 2010) Note that the structures of CNCs changed from an amorphous structure to a multi-walled graphitic layer as the $\mathrm{CNC}$ diameter became small. It was reported that most thin $\mathrm{CNCs}$ with fibre diameter less than $50 \mathrm{~nm}$ had graphite structure. (Kanada et al., 2008), (Lu et al., 2004), (Yang et al., 2003) When the fibre diameter of CNF became small, the fibre formed the multi-walled structure. The change of CNC structure appeared similarly in the reduction of $\mathrm{CNF}$ diameter. The structure change from amorphous to graphitic implies the enhancement of the electrical characteristics of CNCs. It was reported that the electrical resistivity of "graphitic" CNF $\left(\approx 10^{-6} \Omega \mathrm{m}\right)$ (Melechko et al., 2005) was lower than that of "amorphous" carbon micro coil $\left(\approx 10^{-4} \Omega \mathrm{m}\right)$. (Kajihara et al., 2005) 
As the flow rate increased, the amount of carbon deposit, which does not include the mass of metals and zeolite, increased and the fibre became thick, as shown in Figure 24. When the acetylene flow rate and reaction time were $50 \mathrm{ml} / \mathrm{min}$ and $10 \mathrm{~min}$, respectively, the amount of carbon in an acetylene molecule was about $0.5 \mathrm{~g}$. The weight of carbon deposits was about $1-2 \mathrm{mg}$, and about $0.2-0.4 \%$ of carbon was deposited from acetylene. The temperature was varied from $650^{\circ} \mathrm{C}$ to $750^{\circ} \mathrm{C}$ while keeping the $\mathrm{C}_{2} \mathrm{H}_{2}$ flow rate at $50 \mathrm{ml} / \mathrm{min}$. The carbon deposit was highest $(2 \mathrm{mg})$ at $650^{\circ} \mathrm{C}$ and gradually decreased with temperature. However, most of the deposit was CNFs, and CNCs could not be found at $650^{\circ} \mathrm{C}$. CNCs were observed at temperatures of at least $700^{\circ} \mathrm{C}$. The coil pitch of $\mathrm{CNCs}$ grown at $750^{\circ} \mathrm{C}$ was longer than that of $\mathrm{CNCs}$ grown at $700^{\circ} \mathrm{C}$. These results suggest that the $\mathrm{C}_{2} \mathrm{H}_{2}$ flow rate influences not only the yield of MWCNCs in the carbon deposit but also the fibre diameter and $\mathrm{CNC}$ structure.

\subsection{D-TEM analysis of the MWCNC structure and future subject}

Electron tomography of the MWCNC was performed using a TEM tomography system. Reconstruction of 3D image for the MWCNC has been hardly done because there is almost no "marker" on the surface to recognize the rotation of an MWCNC. In this analysis, Au nanoparticles were deposited on MWCNCs by ion sputtering. This helped us recognize the rotation when the tilt angle was changed.

Figure 26(a) shows a TEM micrograph of an MWCNC with Au nanoparticles. The diameters of $\mathrm{Au}$ nanoparticles ranged 1-10 $\mathrm{nm}$. This suggests that MWCNCs are applicable as a support material of nanoparticles. Figure 26(b) shows a reconstructed 3D image of an MWCNC with $\mathrm{Au}$ nanoparticles. From the 3D image, it is confirmed clearly that the MWCNC had a helical shape with a left-hand helix.

Problems still remain in raising the ratio of the MWCNCs to CNTs from $10 \%$. A possible explanation for this experimental observation with SEM is that Fe and Sn nanoparticles were independently supported on different pores of a zeolite. In TEM observation, most MWCNCs did not contain catalyst particles on the end or inside the tube; the catalyst particles inside the tube that we could find contained less than $0.1 \mathrm{wt} \% \mathrm{Sn}$.
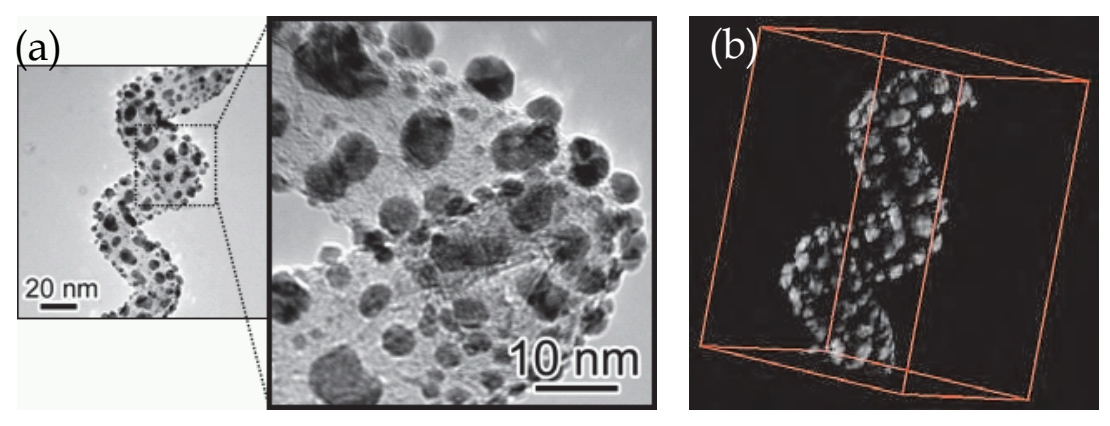

Fig. 26. Electron tomography of an MWCNC. (a) TEM micrograph of the MWCNC coated with Au nanoparticles. (b) Volume rendering image of the reconstructed MWCNC 3D image of (a). These images show that the MWCNC had a helical shape with a left-hand helix. 


\section{Application}

In this section, we introduce an application of HCNF to field emission device. CNTw is used as an electron emitter and mixed with a binder and printed on Si substrate. We have shown that dielectric barrier discharge treatment made CNTws stand up. The field emission property was enhanced by the upright CNTws. (Hosokawa et al., 2008) The detail of experimental conditions is indicated in each of the figure caption.

\subsection{Fabrication of CNTw field emitter}

CNTw was synthesized by catalytic CVD. (Katsumata et al., 2004), (Hosokawa et al., 2007) The CNTws grown were mixed with an organic binder composed of ethyl cellulose in a mortar and the CNTw paste was made. The mixture ratio by weight of CNTw and binder was $7 / 93$. The CNTw paste was screen-printed on a Si substrate measuring $5 \mathrm{~mm} \times 40 \mathrm{~mm}$, and a dot pattern of CNTw film (dot size $=100 \mu \mathrm{m} \times 100 \mu \mathrm{m}$, spacing $=100 \mu \mathrm{m}$ ) was formed. The CNTw film was calcined in an electric furnace at $120^{\circ} \mathrm{C}$ for $2 \mathrm{~h}$ or $400^{\circ} \mathrm{C}$ for $1 \mathrm{~h}$. (Lee et al., 2006) The film thickness after the calcination was $3 \mu \mathrm{m}$. To measure the field emission property, $\mathrm{Zn}: \mathrm{ZnO}$ phosphor was used as an anode, and the anode area, gap distance and pressure were $0.1 \mathrm{~cm}^{2}(\phi 3.6 \mathrm{~mm}), 100 \mathrm{~mm}$ and $10^{-4} \mathrm{~Pa}$, respectively.

\subsection{Stand-up treatment}

The CNTw emitter was treated by a dielectric barrier discharge (DBD) apparatus as shown in Figure 27. A quartz plate was glued on both electrode surfaces and DBD was generated between the plates $(\mathrm{Xu}, 2001)$. In He gas, the glow discharge was uniformly generated ('glow mode'), whereas DBD was seen in $\mathrm{N}_{2}$ ('filament mode'). In this study, both modes were applied to the CNTw emitter. The emitter was placed on the grounded electrode and treated by generating a discharge on the substrate surface (Figure 28). The following treatment conditions were commonly used: the gap distance (distance from the emitter surface to the upper electrode) $=1 \mathrm{~mm}$, discharge frequency $=30 \mathrm{kHz}$, pulse duration $=2.0 \mu$ s and gas flow rate $=2000 \mathrm{ml} / \mathrm{min}$. For 'glow mode,' He gas was used, and an electric field of $4.4 \mathrm{kV} / \mathrm{mm}$ was applied for $30 \mathrm{~s}$. On the other hand, $\mathrm{N}_{2}$ gas was used and an electric field of $6.8 \mathrm{kV} / \mathrm{mm}$ was applied for 'filament mode.' The treatment time was varied from 0 to $180 \mathrm{~s}$. The filaments between the electrodes move randomly while the discharge is sustained. Therefore, it is possible to treat the whole area of the substrate uniformly if the size of the substrate is smaller than that of the dielectric plate.

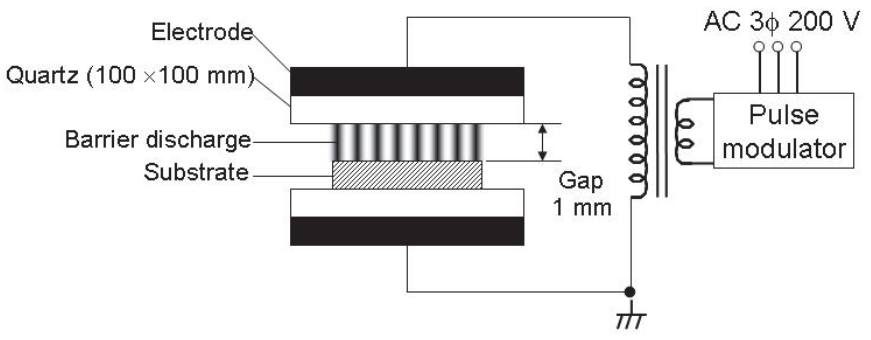

Fig. 27. Schematic of dielectric barrier discharge (DBD) apparatus. (Hosokawa et al., 2008) 

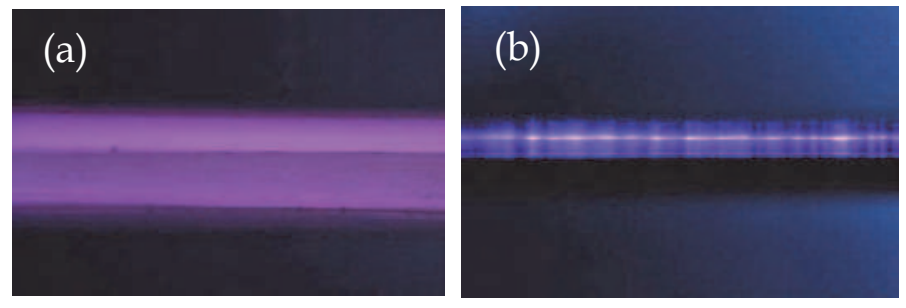

Fig. 28. Photographs of stand-up treatment by $(a)$ 'glow mode' and $(b)$ 'filament mode.' (Hosokawa et al., 2008)

\subsection{Making CNTws stand up}

Figure 29 shows an SEM micrograph of the emitter treated by 'glow mode.' The surface does not seem changed by 'glow mode' treatment, and CNTws remain tangled and heaped on the substrate. On the other hand, by 'filament mode' treatment, the CNTws were made to stand vertically from the substrate, as shown in Figure 30. For a treatment time $\geq 30 \mathrm{~s}$, flocculated CNTws are not seen any more, and it is confirmed that 3-5 CNTws are upright at $5 \mu \mathrm{m}$ intervals on the emitter treated for 30 and $60 \mathrm{~s}$. Their length from the substrate surface became shorter due to etching as the treatment time increased. The great difference in the treatment results between the 'glow' and 'filament' modes is clearly shown in Figures 29 and 30. To explain this, the orientation forces applied to CNTws in each mode are illustrated in Figure 31. The electric field is almost uniform in the vertical direction from the substrate in the 'glow mode' (Figure 31(a)) and Coulomb force:

$$
F=q E,
$$

where $q$ is the electric charge on CNTws; $E$ the electric field only acts on CNTws. On the other hand, in the 'filament mode,' a non-uniform electric field is generated between the electrodes, and not only the Coulomb force but also the gradient force

$$
F=\frac{1}{2} \operatorname{grad}\left(E^{2} \rho_{m} \frac{\partial \varepsilon}{\partial \rho_{m}}\right),
$$

where $\varepsilon$ is the permittivity of $\mathrm{CNTw} ; \rho_{\mathrm{m}}$ the density of CNTw acts on CNTws in the direction in which the electric field strength is increasing. (Stratton, 1941) The gradient force in the 'filament mode' is larger than the Coulomb force since the gradient force is proportional to the gradient of the product of permittivity and electric field squared. Consequently, CNTws could be raised by the gradient force in the 'filament mode.'

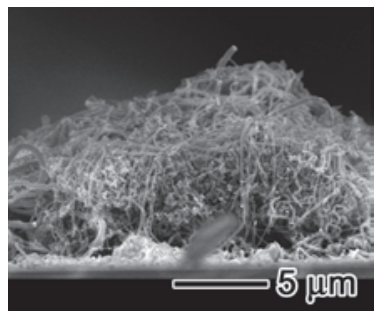

Fig. 29. SEM micrograph of the emitter treated by 'glow mode.' (Hosokawa et al., 2008) 

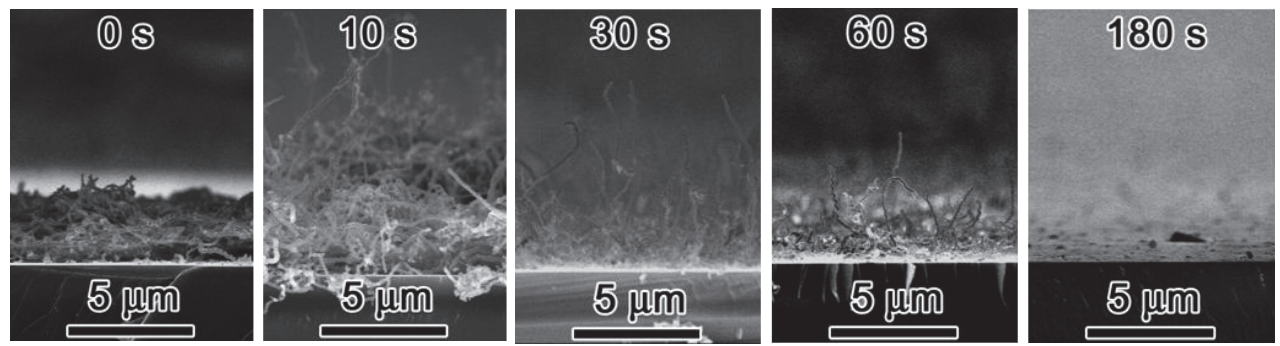

Fig. 30. SEM micrographs of the emitter treated by 'filament mode' at different treatment times. (Hosokawa et al., 2008)

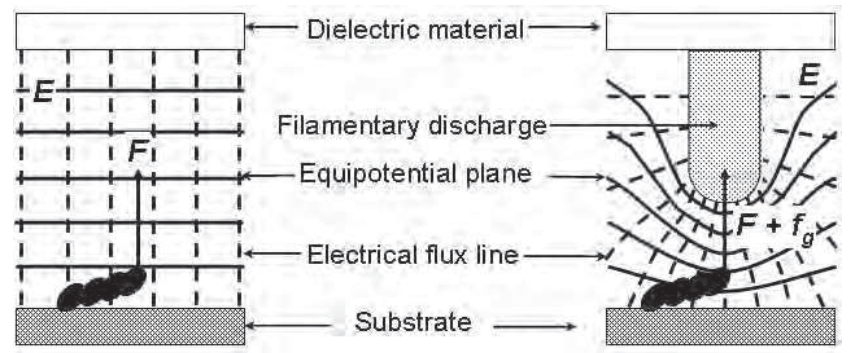

Fig. 31. Schematic illustrations of orientation force on CNTw: (a) uniform electric field in 'glow mode,' (b) non-uniform electric field in 'filament mode.' (Hosokawa et al., 2008)

\subsection{Field emission property}

Figure 32 shows the field emission properties of the CNTw emitter treated by the 'filament mode' and emission pattern at a maximum current. Before the treatment, a spark easily occurred at a low electric field. The treatment made the field emission current higher. The field emission properties of the emitter at different treatment times are listed in Table 2. With emitter treatment for $10 \mathrm{~s}$, the emission site is not uniformly distributed as shown in Figure 32. By the $30 \mathrm{~s}$ treatment, the emission is not concentrated but uniformly spread and the field emission properties are greatly enhanced. The ratio of the emitting area of the sample treated for $30 \mathrm{~s}$ to the phosphor surface reached $57 \%$ though that of the untreated sample was $2 \%$ only. As shown in Table 2, the length of CNTws was also gradually decreased and the distribution of CNTw length was narrowed due to etching with an increase in treatment time. This indicates that the treatment by 'filament mode' serves to flatten the emitter tips as well as make them stand up. However, the number of CNTws by the $60 \mathrm{~s}$ treatment was decreased and it made the field emission virtually impossible. Field emission did not occur from the $180 \mathrm{~s}$ treated emitter because mostly CNTws were removed. Also, we tried to treat the emitters composed of conductive/nonconductive whiskers and CNTs by the 'filament mode' and confirmed that the conductive whiskers were made to stand up. The CNTs were easily removed just after the ignition of DBD. A possible explanation for this is that the diameter of CNTs used was much thinner ( $10 \mathrm{~nm})$ than that of CNTws. Therefore, this stand-up treatment by DBD would be suitable for thick CNFs. 


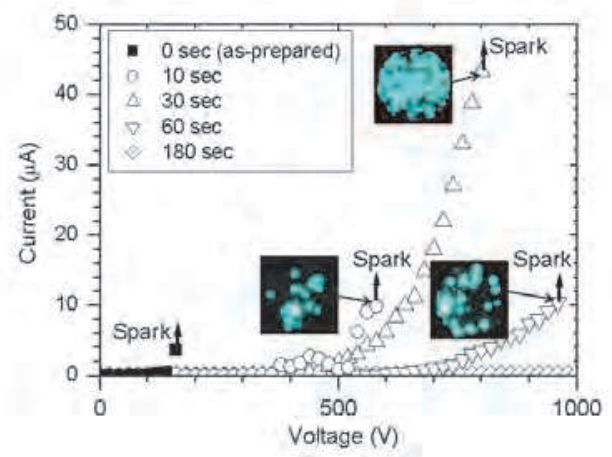

Fig. 32. Field emission property of the CNTw emitter treated by 'filament mode' at different treatment times. Inset photos show the emission pattern from each CNTw emitter.

(Hosokawa et al., 2008)

\begin{tabular}{cccc}
\hline $\begin{array}{c}\text { Treatment } \\
\text { time }(\mathrm{s})\end{array}$ & $\begin{array}{c}\text { Threshold electric field for field } \\
\text { emission current }=1 \mu \mathrm{A}(\mathrm{V} / \mu \mathrm{m})\end{array}$ & $\begin{array}{c}\text { Maximum current } \\
\text { density }\left(\mathrm{mA} / \mathrm{cm}^{2}\right)\end{array}$ & $\begin{array}{c}\text { CNTw length } \\
(\mu \mathrm{m})\end{array}$ \\
\hline 0 & 1.5 & $0.037($ at $160 \mathrm{~V})$ & $5-10$ \\
10 & 5.2 & $0.098($ at $580 \mathrm{~V})$ & $5-10$ \\
30 & 4.6 & $0.433($ at $800 \mathrm{~V})$ & $3.6-5.4$ \\
60 & 7.0 & $0.105($ at $960 \mathrm{~V})$ & $1-3$ \\
180 & Not measured & $0.003($ at $1000 \mathrm{~V})$ & 0 \\
\hline
\end{tabular}

Table 2. Field emission property of the CNTw emitter at different treatment times. As for the untreated CNTws, we measured the length of powdery CNTws before fabricating the emitter. (Hosokawa et al., 2008)

\section{Conclusion}

We have shown that HCNFs are grown by CVD and that their dimension and types can be controlled by binary catalysts and CVD conditions. There are many possible HCNF applications to a wide area of nanoelectronics and nanomechanics industries. An example of $\mathrm{HCNF}$ application as an electron field emitter was introduced in this chapter. We have been trying to apply HCNF as a catalyst support in fuel cell and such a new application case is expected to appear.

\section{Acknowledgements}

We would like to thank to our collaborator: Mr. H. Ue of Tokai Carbon Co., Ltd., Mr. K. Shimizu of Shonan Plastic Mfg. Co., Ltd., and Mr. Y. Umeda of Toho Gas Co., Ltd. for their support. We also thank to our students: Mr. Y. Hosokawa, Mr. M. Yokota, Mr. K. Takimoto, Ms. L.S. Ling, Mr. Y. Sugioka, and Mr. Y. Ishii for their experimental work. The technical support for microscopy observation by Dr. T. Hamanaka of Japan Fine Ceramics Center (JFCC) and Mr. K. Muramoto of Toyohashi University of Technology is greatly 
acknowledged. This work has been partly supported by the Research Project of the Venture Business Laboratory from Toyohashi University of Technology (Toyohashi Tech); Global COE Program "Frontier of Intelligent Sensing" from the Ministry of Education, Culture, Sport, Science and Technology (MEXT); Core University Programs (JSPS-CAS program in the field of "Plasma and Nuclear Fusion") from The Japan Society for the Promotion of Science (JSPS); Grant-in-Aid for Young Scientists (B) from MEXT; Toukai Foundation for Technology; Research Foundation for Materials Science; Chubu Science and Technology Center; and CASIO Science Promotion Foundation.

\section{References}

Amelinckx, S.; Zhang, X.B.; Bernaerts, D.; Zhang, X.F.; Ivanov, V. \& Nagy, J.B. (1994). A Formation Mechanism for Catalytically Grown Helix-Shaped Graphite Nanotubes, Science, Vol.265, No.5172, (July 1994), pp. 635-639, ISSN 0036-8075

Baker, R.T.K.; Barber, M.A.; Harris, P.S.; Feates, F.S. \& Waite, R.J. (1972). Nucleation and Growth of Carbon Deposits from the Nickel Catalyzed Decomposition of Acetylene, Journal of Catalysis, Vol.26, No.1, (July 1972), pp. 51-62, ISSN 0021-9517

Baker, R.T.K.; Harris, P.S. \& Terry, S. (1975). Unique Form of Filamentous Carbon. Nature, Vol.253, No.5486, (January 1975), pp. 37-39, ISSN 0028-0836

Baker, R.T.K. (1989). Catalytic Growth of Carbon Filaments, Carbon, Vol.27, No.3, (1989), pp. 315-323, ISSN 0008-6223

Bell, A.T. \& Shustorovich, E. (1990). Analysis of the Thermochemistry of $C_{2}$ Hydrocarbons on Transition Metal Surfaces Using a Refined BOC-MP Approach, Surface Science, Vol.235, Nos.2-3, (September 1990), pp. 343-350, ISSN 0039-6028

Boehm, H.P. (1973). Carbon from Carbon Monoxide Disproportionation on Nickel and Iron Catalysts: Morphological Studies and Possible Growth Mechanism. Carbon, Vol.11, No.6, (December 1973), pp. 583-590, ISSN 0008-6223

Chen, B.; Fujimura, Y.; Katsumata, T.; Takikawa, H.; Hibi, Y.; Sakakibara, T. \& Itoh, S. (2004). Effect of Multi-Catalysts on Carbon Nanofiber Synthesis in CVD, Transactions of the Materials Research Society of Japan, Vol.29, No.2, (March 2004), pp. 559-562

Davis, W.R.; Slawson, R.J. \& Rigby, G.R. (1953). An Unusual Form of Carbon. Nature, Vol.171, No.4356, (April 1953), p. 756, ISSN 0028-0836

Delzeit, L.; McAninch, I.; Cruden, B.A.; Hash, D.; Chen, B.; Han, J. \& Meyyappan, M. (2002). Growth of Multiwall Carbon Nanotubes in an Inductively Coupled Plasma Reactor, Journal of Applied Physics, Vol.91, No.9, (May 2002), pp. 6027-6033, ISSN 0021-8979

Fonseca, A.; Hernadi, K.; Nagy, J.B.; Lambin, Ph. \& Lucas, A.A. (1995). Model Structure of Perfectly Graphitizable Coiled Carbon Nanotubes, Carbon, Vol.33, No.12, (1995), pp. 1759-1775, ISSN 0008-6223

Fonseca, A.; Hernadi, K.; Nagy, J.B.; Lambin, Ph. \& Lucas, A.A. (1996). Growth Mechanism of Coiled Carbon Nanotubes, Synthetic Metals, Vol.77, Nos.1-3, (February 1996), pp. 235-242, ISSN 0379-6779

Hanus, M.J. \& Harris, A.T. (2010). Synthesis, Characterisation and Applications of Coiled Carbon Nanotubes, The Journal of Nanoscience and Nanotechnology, Vol.10, No.4, (April 2010), pp. 2261-2283, ISSN 1533-4880

Hernadi, K.; Fonseca, A.; Nagy, J.B.; Fudala, A.; Bernaerts, D. \& Kiricsi, I. (2002). Catalytic Production of Carbon Nanofibers over Iron Carbide Doped with $\mathrm{Sn}^{2+}$, Applied Catalysis A, Vol.228, Nos.1-2, (March 2002), pp. 103-113, ISSN 0926-860X 
Hofer, L.J.E.; Sterling, E. \& McCartney, J.T. (1955). Structure of the Carbon Deposited from Carbon Monoxide on Iron, Cobalt and Nickel. The Journal of Physical Chemistry, Vol.59, No.11, (November 1955), pp. 1153-1155, ISSN 0022-3654

Hokshin, S.; Pan, L. \& Nakayama, Y. (2007). Diameter Control of Carbon Nanocoils by the Catalyst of Organic Metals, Japanese Journal of Applied Physics, Vol.46, No.8A, (August 2007), pp. 5383-5385, ISSN 0021-4922

Hosokawa, Y.; Shiki, H.; Shinohara, Y.; Yokota, M.; Takikawa, H.; Ina, T.; Okada, F.; Fujimura, Y.; Yamaura, T.; Itoh, S.; Miura, K. \& Yoshikawa, K. (2007). Preparation of Powdery Carbon Nanotwist and Application to Printed Field Emitter, Research Letters in Materials Science, Vol.2007, (2007), 59167, ISSN 1687-6822

Hosokawa, Y.; Shinohara, Y.; Yokota, M.; Shiki, H.; Suda, Y.; Oke, S.; Takikawa, H.; Ina, T.; Morioki, M.; Fujimura, Y.; Yamaura, T.; Itoh, S. \& Miura, K. (2008). Filament discharge enhances field emission properties by making twisted carbon nanofibres stand up, Journal of Physics D: Applied Physics, Vol.41, No.20 (October 2008) 205418, ISSN 0022-3727

Hung, W.H. \& Bernasek, S.L. (1995). Adsorption and Decomposition of Ethylene and Acetylene on Fe(100), Surface Science, Vol.339, No.3, (October 1995), pp. 272-290, ISSN 0039-6028

Iijima, S. (1991). Helical Mircotubules of Graphitic Carbon. Nature, Vol.354, No.6348, (November 1991), pp. 56-58, ISSN 0028-0836

Iijima, S. \& Ichihashi, T. (1993). Single-Shell Carbon Nanotubes of 1-nm Diameter. Nature, Vol.363, No.6430, (June 1993), pp. 603-605, ISSN 0028-0836

Ivanov, V.; Nagy, J.B.; Lambin, Ph.; Lucas, A.; Zhang, X.B.; Zhang, X.F.; Bernaerts, D.; Van Tendeloo, G.; Amelinckx, S. \& Van Landuyt, J. (1994). The Study of Carbon Nanotubules Produced by Catalytic Method. Chemical Physics Letters, Vol.223, No.4, (June 1994), pp. 329-335, ISSN 0009-2614

Jong, K.P.D. \& Geus, J.W. (2000). Carbon Nanofibres: Catalytic Synthesis and Applications, Catalysis Reviews -Science and Engineering, Vol.42, No.4, (2000), pp. 481-510, ISSN 0161-4940

Journet, C.; Maser, W.K.; Bernier, P.; Loiseau, A.; Lamyde la Chapelle, M.; Lefrant, S.; Deniard, P.; Leek, R. \& Fischerk, J.E. (1997). Large-Scale Production of SingleWalled Carbon Nanotubes by the Electric-Arc Technique. Nature, Vol.388, No.6644, (August 1997), pp. 756-758, ISSN 0028-0836

Kanada, R.; Pan, L.; Akita, S.; Okazaki, N.; Hirahara, K. \& Nakayama, Y. (2008). Synthesis of Multiwalled Carbon Nanocoils Using Codeposited Thin Film of Fe-Sn as Catalyst, Japanese Journal of Applied Physics, Vol.47, No.4 (April 2008), pp. 1949-1951, ISSN 0021-4922

Kajihara, Y.; Hihara, T.; Sumiyama, K. \& Motojima, S. (2005). Electrical Resistivity of Carbon Micro Coil Measured by a Multi-Probe Unit Installed in a Scanning Electron Microscope, Japanese Journal of Applied Physics, Vol.44, No.9A (September 2005), pp. 6867-6869, ISSN 0021-4922

Katsumata, T.; Fujimura, Y.; Nagayama, M.; Tabata, H.; Takikawa, H.; Hibi, Y.; Sakakibara, T. \& Itoh, S. (2004). Synthesis of Twisted Carbon Nanofiber by Catalytic CVD Method, Transactions of the Materials Research Society of Japan, Vol.29, No.2, (March 2004), pp. 501-504

Kim, M.S.; Rodriguez, N.M. \& Baker, R.T.K. (1992). The Role of Interfacial Phenomena in the Structure of Carbon Deposits, Journal of Catalysis, Vol.134, No.1, (March 1992), pp. 253-268, ISSN 0021-9517 
Kong, J.; Cassell, A.M. \& Dai, H. (1998). Chemical Vapor Deposition of Methane for SingleWalled Carbon Nanotubes. Chemical Physics Letters, Vol.292, Nos.4-6, (August 1998), pp. 567-574, ISSN 0009-2614

Kumar, M. \& Ando, Y. (2010). Chemical Vapor Deposition of Carbon Nanotubes: A Review on Growth Mechanism and Mass Production, The Journal of Nanoscience and Nanotechnology, Vol.10, No.6, (June 2010), pp. 3739-3758, ISSN 1533-4880

Lee, H.J.; Lee, Y.D.; Moon, S.I.; Cho, W.S.; Lee, Y.H.; Kim, J.K.; Hwang, S.W. \& Ju, B.K. (2006). Enhanced surface morphologies of screen-printed carbon nanotube films by heat treatment and their field-emission properties, Carbon, Vol.44, No.13 (November 2006), pp. 2625-2630, ISSN 0008-6223

Lee, Y.T.; Kim, N.S.; Park, J.; Han, J.B.; Choi, Y.S.; Ryu, H. \& Lee, H.J. (2003). TemperatureDependent Growth of Carbon Nanotubes by Pyrolysis of Ferrocene and Acetylene in the Range between 700 and $1000^{\circ} \mathrm{C}$, Chemical Physics Letters, Vol.372, Nos.5-6, (May 2003), pp. 853-859, ISSN 0009-2614

Lu, M.; Liu, W.; Guo, X. \& Li, H. (2004). Coiled Carbon Nanotubes Growth via ReducedPressure Catalytic Chemical Vapor Deposition, Carbon, Vol.42, No.4 (2004), pp. 805811, ISSN 0008-6223

Melechko, A.V.; Merkulov, V.I.; McKnight, T.E.; Guillorn, M.A.; Klein, K.L.; Lowndes, D.H. \& Simpson, M.L. (2005). Vertically Aligned Carbon Nanofibers and Related Structures: Controlled Synthesis and Directed Assembly, Journal of Applied Physics, Vol.97, No.4 (February 2005), 041301, ISSN 0021-8979

Motojima, S.; Ueno, S.; Hattori, T. \& Goto, K. (1989). Growth of Regularly Coiled Spring-Like Fibers of $\mathrm{Si}_{3} \mathrm{~N}_{4}$ by Iron Impurity-Activated Chemical Vapor Deposition. Applied Physics Letters, Vol.54, No.11, (March 1989), pp. 1001-1003, ISSN 0003-6951

Motojima, S.; Kawaguchi, M.; Nozaki, K. \& Iwanaga, H. (1990). Growth of Regularly Coiled Carbon Filaments by Ni Catalyzed Pyrolysis of Acetylene, and Their Morphology and Extension Characteristics. Applied Physics Letters, Vol.56, No.4, (January 1990), pp. 321-323, ISSN 0003-6951

Motojima, S. \& Chen, X. (2004). Nanohelical/Sprial Materials, In: Encyclopedia of Nanoscience and Nanotechnology, Nalwa, H. S., (Ed.), Vol.6, pp. 775-794, American Science Publishers, ISBN 1-58883-001-2, Stevenson Ranch, California, USA

Nolan, P.E.; Schabel, M.J.; Lynch, D.C. \& Cutler, A.H. (1995). Hydrogen Control of Carbon Deposit Morphology, Carbon, Vol.33, No.1, (1995), pp. 79-85, ISSN 0008-6223

Pan, L.; Zhang, M. \& Nakayama, Y. (2002). Growth Mechanism of Carbon Nanocoils, Journal of Applied Physics, Vol.91, No.12, (June 2002), pp. 10058-10061, ISSN 0021-8979

Qin, L.C. (1997). CVD Synthesis of Carbon Nanotubes, Journal of Materials Science Letters, Vol.16, (1997), pp. 457-459, ISSN 1573-4811

Rodriguez, N.M. (1993). A Review of Catalytically Grown Carbon Nanofibers, Journal of Materials Research, Vol.8, No.12, (December 1993), pp. 3233-3250, ISSN 0884-2914

Rodriguez, N.M.; Chambers, A. \& Baker, R.T.K. (1995). Catalytic Engineering of Carbon Nanostructures, Langmuir, Vol.11, No.10, (October 1995), pp. 3862-3866, ISSN 07437463

Saito, R.; Dresselhaus, G. \& Dresselhaus, M.S. (1998). Physical Properties of Carbon Nanotube, Imperial College Press, ISBN 978-1860942235, London, UK

Smithells, C.J. (1992). Smithells Metals Reference Book, Brandes, E.A. \& Brook, G.B., (Eds.), Butterworth-Heinemann, ISBN 978-0750675093, London, UK

Stratton, J.A. (1941). Electromagnetic Theory, McGraw-Hill, ISBN 978-0070621503, New York/London 
Takikawa, H.; Shinsako, K. \& Sakakibara, T. (1998). TiN/Ti Film Formation by Vacuum Arc Deposition with Droplet Shield Plate, Thin Solid Films, Vol.316, Nos.1-2, (March 1998), pp. 73-78, ISSN 0040-6090

Takikawa, H.; Yatsuki, M.; Miyano, R.; Nagayama, M.; Sakakibara, T.; Itoh, S. \& Ando, Y. (2000). Amorphous Carbon Fibrilliform Nanomaterials Prepared by Chemical Vapor Deposition, Japanese Journal of Applied Physics, Vol.39, No.9A, (September 2000), pp. 5177-5179, ISSN 0021-4922

Thess, A.; Lee, R.; Nikolaev, P.; Dai, H.; Petit, P.; Robert, J.; Xu, C.; Lee, Y.H.; Kim, S.G.; Rinzler, A.G.; Colbert, D.T.; Scuseria, G.E.; Tománek, D.; Fischer, J.E.; \& Smalley, R.E. (1996). Crystalline Ropes of Metallic Carbon Nanotubes. Science, Vol.273, No.5274, (July 1996), pp. 483-487, ISSN 0036-8075

Xu, G.; Chen, B.; Shiki, H.; Katsumata, T.; Takikawa, H.; Sakakibara, T.; Itoh, S. \& Ina, T. (2005). Parametric Study on Growth of Carbon Nanocoil by Catalytic Chemical Vapor Deposition, Japanese Journal of Applied Physics, Vol.44, No.4A, (April 2005), pp. 1569-1576, ISSN 0021-4922

$\mathrm{Xu}, \mathrm{X}$. (2001). Dielectric barrier discharge-properties and applications, Thin Solid Films, Vol.390, Nos.1-2 (June 2001), pp. 237-242, ISSN 0040-6090

Xu, X. \& Pacey, P.D. (2001). An Induction Period in the Pyrolysis of Acetylene, Physical Chemistry Chemical Physics, Vol.3, No.14, (2001), pp. 2836-2844, ISSN 1463-9076

Yang, S.; Chen, X. \& Motojima, S. (2004). Morphology of the Growth Tip of Carbon Microcoils/Nanocoils, Diamond and Related Materials, Vol.13, Nos.11-12, (November-December 2004), pp. 2152-2155, ISSN 0925-9635

Yang, S.; Chen, X., Motojima, S. \& Ichihara, M. (2005). Morphology and Microstructure of Spring-Like Carbon Micro-Coils/Nano-Coils Prepared by Catalytic Pyrolysis of Acetylene Using Fe-Containing Alloy Catalysts, Carbon, Vol.43, No.4, (2005), pp. 827-834, ISSN 0008-6223

Yang, Y.; Hu, Z.; Lu, Y.N. \& Chen, Y. (2003). Growth of Carbon Nanotubes with MetalLoading Mesoporous Molecular Sieves Catalysts, Materials Chemistry and Physics, Vol.82, No.2 (November 2003), pp. 440-443, ISSN 0254-0584

Yokota, M.; Shinohara, Y.; Kawabata, T.; Takimoto, K.; Suda, Y.; Oke, S.; Takikawa, H.; Fujimura, Y.; Yamaura, T.; Itoh, S.; Miura, K. \& Morioki, M. (2010). Splitting and Flattening of Helical Carbon Nanofibers by Acid Treatment, The Journal of Nanoscience and Nanotechnology, Vol.10, No.6, (June 2010), pp. 3910-3914, ISSN 15334880

Yokota, M.; Suda, Y.; Takikawa, H.; Ue, H.; Shimizu, K. \& Umeda, Y. (2011). Structural Analysis of Multi-Walled Carbon Nanocoils Synthesized with Fe-Sn Catalyst Supported on Zeolite, The Journal of Nanoscience and Nanotechnology, Vol.11, No.3 (March 2011), pp. 2344-2348, ISSN 1533-4880

Yu, Q., Lian, J., Siriponglert, S., Li, H., Chen, Y.P. \& Pei, S.-S. (2008). Graphene Segregated on Ni Surfaces and Transferred to Insulators, Applied Physics Letters, Vol.93, No.11, (September 2008), 113103, ISSN 0003-6951

Zhang, M.; Nakayama, Y. \& Pan, L. (2000). Synthesis of Carbon Tubule Nanocoils in High Yield Using Iron-Coated Indium Tin Oxide as Catalyst, Japanese Journal of Applied Physics, Vol.39, No.12A, (December 2000), pp. L1242-L1244, ISSN 0021-4922 


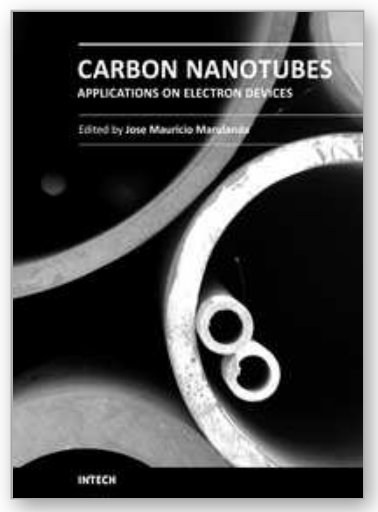

\section{Carbon Nanotubes Applications on Electron Devices}

Edited by Prof. Jose Mauricio Marulanda

ISBN 978-953-307-496-2

Hard cover, 556 pages

Publisher InTech

Published online 01, August, 2011

Published in print edition August, 2011

Carbon nanotubes (CNTs), discovered in 1991, have been a subject of intensive research for a wide range of applications. In the past decades, although carbon nanotubes have undergone massive research, considering the success of silicon, it has, nonetheless, been difficult to appreciate the potential influence of carbon nanotubes in current technology. The main objective of this book is therefore to give a wide variety of possible applications of carbon nanotubes in many industries related to electron device technology. This should allow the user to better appreciate the potential of these innovating nanometer sized materials. Readers of this book should have a good background on electron devices and semiconductor device physics as this book presents excellent results on possible device applications of carbon nanotubes. This book begins with an analysis on fabrication techniques, followed by a study on current models, and it presents a significant amount of work on different devices and applications available to current technology.

\section{How to reference}

In order to correctly reference this scholarly work, feel free to copy and paste the following:

Yoshiyuki Suda, Hirofumi Takikawa and Hideto Tanoue (2011). Syntheses and Electronic Applications of Helical Carbon Nanofibers, Carbon Nanotubes Applications on Electron Devices, Prof. Jose Mauricio Marulanda (Ed.), ISBN: 978-953-307-496-2, InTech, Available from: http://www.intechopen.com/books/carbonnanotubes-applications-on-electron-devices/syntheses-and-electronic-applications-of-helical-carbonnanofibers

\section{INTECH}

open science | open minds

\section{InTech Europe}

University Campus STeP Ri

Slavka Krautzeka 83/A

51000 Rijeka, Croatia

Phone: +385 (51) 770447

Fax: +385 (51) 686166

www.intechopen.com

\section{InTech China}

Unit 405, Office Block, Hotel Equatorial Shanghai

No.65, Yan An Road (West), Shanghai, 200040, China

中国上海市延安西路65号上海国际贵都大饭店办公楼405单元

Phone: +86-21-62489820

Fax: $+86-21-62489821$ 
(C) 2011 The Author(s). Licensee IntechOpen. This chapter is distributed under the terms of the Creative Commons Attribution-NonCommercialShareAlike-3.0 License, which permits use, distribution and reproduction for non-commercial purposes, provided the original is properly cited and derivative works building on this content are distributed under the same license. 